\title{
Systems analysis of human brain gene expression: mechanisms for HIV-associated neurocognitive impairment and common pathways with Alzheimer's disease
}

Andrew J Levine ${ }^{1^{*}+}$, Jeremy A Miller ${ }^{2 \dagger}$, Paul Shapshak ${ }^{3}$, Benjamin Gelman ${ }^{4}$, Elyse J Singer ${ }^{1}$, Charles H Hinkin ${ }^{5,6}$, Deborah Commins ${ }^{7}$, Susan Morgello ${ }^{8}$, Igor Grant ${ }^{9}$ and Steve Horvath 2,10

\begin{abstract}
Background: Human Immunodeficiency Virus-1 (HIV) infection frequently results in neurocognitive impairment. While the cause remains unclear, recent gene expression studies have identified genes whose transcription is dysregulated in individuals with HIV-association neurocognitive disorder (HAND). However, the methods for interpretation of such data have lagged behind the technical advances allowing the decoding genetic material. Here, we employ systems biology methods novel to the field of NeuroAIDS to further interrogate extant transcriptome data derived from brains of HIV + patients in order to further elucidate the neuropathogenesis of HAND. Additionally, we compare these data to those derived from brains of individuals with Alzheimer's disease (AD) in order to identify common pathways of neuropathogenesis.

Methods: In Study 1, using data from three brain regions in 6 HIV-seronegative and 15 HIV + cases, we first employed weighted gene co-expression network analysis (WGCNA) to further explore transcriptome networks specific to HAND with HIV-encephalitis (HIVE) and HAND without HIVE. We then used a symptomatic approach, employing standard expression analysis and WGCNA to identify networks associated with neurocognitive impairment $(\mathrm{NCl})$, regardless of HIVE or HAND diagnosis. Finally, we examined the association between the CNS penetration effectiveness (CPE) of antiretroviral regimens and brain transcriptome. In Study 2, we identified common gene networks associated with $\mathrm{NCl}$ in both HIV and AD by correlating gene expression with pre-mortem neurocognitive functioning.

Results: Study 1: WGCNA largely corroborated findings from standard differential gene expression analyses, but also identified possible meta-networks composed of multiple gene ontology categories and oligodendrocyte dysfunction. Differential expression analysis identified hub genes highly correlated with $\mathrm{NCl}$, including genes implicated in gliosis, inflammation, and dopaminergic tone. Enrichment analysis identified gene ontology categories that varied across the three brain regions, the most notable being downregulation of genes involved in mitochondrial functioning. Finally, WGCNA identified dysregulated networks associated with NCl, including oligodendrocyte and mitochondrial functioning. Study 2: Common gene networks dysregulated in relation to $\mathrm{NCl}$ in $A D$ and HIV included mitochondrial genes, whereas upregulation of various cancer-related genes was found. (Continued on next page)
\end{abstract}

\footnotetext{
* Correspondence: ajlevine@mednet.ucla.edu

${ }^{\dagger}$ Equal contributors

'Department of Neurology, National Neurological AIDS Bank, David Geffen

School of Medicine at the University of California, Los Angeles, CA, USA

Full list of author information is available at the end of the article
} 
(Continued from previous page)

Conclusions: While under-powered, this study identified possible biologically-relevant networks correlated with $\mathrm{NCl}$ in HIV, and common networks shared with AD, opening new avenues for inquiry in the investigation of HAND neuropathogenesis. These results suggest that further interrogation of existing transcriptome data using systems biology methods can yield important information.

Keywords: HIV encephalitis, HIV-associated dementia, HIV-associated neurocognitive disorder, Weighted gene coexpression network analysis, WGCNA, CNS penetration effectiveness, National neuroAIDS tissue consortium, Coexpression module

\section{Background}

Infection with Human Immunodeficiency Virus-1 (HIV) frequently leads to neurologic consequences that are heterogeneous both behaviorally and pathologically. Behaviorally, some individuals will develop HIV-associated neurocognitive disorder (HAND), a syndrome of widely varying severity with unclear neuropathogenesis [1]. In some individuals with HAND, pathological evidence of encephalitis, termed HIV-encephalitis (HIVE), is seen upon autopsy; however, the correlation between HAND and HIVE is modest at best [2,3]. To investigate the neuropathogenesis of HIVE and HAND, several methodologies have been employed, including measurements of gene expression alterations using. To date, most transcriptome studies utilizing brains of HIV-infected (HIV+) humans have focused on gene expression changes underlying HIVE. Such studies, generally limited to examination of the frontal grey matter, have found altered regulation of genes involved in neuroimmune functioning, and also implicated neurodegenerative pathways based on dysregulation of genes involved in synapto-dendritic functioning and integrity [4], toll-like receptors [5], and interferon response [6]. As recently reviewed [7], findings from human microarray studies have been partially replicated in simian immunodeficiency virus models, especially with regards to interferon-related and neuroinflammatory-related genes $[8,9]$. Mouse astrocytes exposed to HIV have also shown some transcription overlap with those of simian and human studies [10]. More recently, in an analysis of gene microarray data derived from multiple brain regions of HIV + individuals with HAND alone or HAND with HIVE, two apparently distinct transcriptome profiles were found, suggesting that there may be two etiological pathways to HAND [11]. Specifically, HIVE with concomitant HAND was associated with high brain viral load, upregulation of inflammatory pathways across all brain regions, and downregulation of neuronal transcripts in frontal neocortex. Conversely, HAND without HIVE was characterized by low brain HIV burden without evidence of increased inflammatory response, and without downregulation of transcripts in frontal neocortical neurons. Indeed, only transcripts characteristically expressed by vascular and perivascular-type cells were consistently dysregulated in HAND without HIVE. Taken together, the results of that most recent and comprehensive study of $\mathrm{HIV}+$ brain transcriptome suggests divergent neuropathogenic gene expression signatures reflecting different pathways underlying HAND with HIVE as compared to HAND without HIVE (see also Gelman and Moore [12]).

While these studies have provided important information, further interrogation of the data may provide further insight into the pathogenesis of HAND and HIVE. Thus far, analysis of transcriptome data has involved comparing gene transcript levels between groups and then determining the gene ontology of those genes that demonstrate significant differences in expression. However, because genes function in biologically-related networks, and therefore are likely to exhibit correlated expression, this method may overlook important aspects of disease pathogenesis. Further, while similarities may be observed in the expression of specific genes across species, these genes may be involved in different biological pathways in the species examined, confounding interpretation. As such, despite the diversity of microarray studies of HIV+ brains within and across species, no coherent picture of transcriptome aberrations has emerged. In the current study, we apply weighted gene co-expression network analysis (WGCNA), a proven systems biology methodology, to an existing gene expression data set derived from HIV + human brains [13-15]. WGCNA enables a more systematic and global interpretation of gene expression data, identifying biologically meaningful 'modules' that are often comprised of functionally related genes and/or correspond to cell types [16]. This is accomplished by assessing gene co-expression patterns (i.e., correlation matrices). The focus on co-expression modules, each consisting of possibly hundreds of genes with common co-expression across samples, allows for a biologically motivated reduction of data while also alleviating the problem of multiple comparisons. Typically, WGCNA results in fewer than 20 modules (as opposed to thousands of genes), which can then be examined for their association to clinical or biological variables of interest. Given the limited sample size of most transcriptome studies, a module based analysis is not only biologically 
meaningful but also attractive from a statistical point of view. An advantage of WGCNA vis-a-vis alternative coexpression based analyses is the availability of powerful module preservation statistics which can be used to quantitate the extent to which disease related modules are present in other data sets, including other species, or other organs and cells within the same organism [17-19]. Finally, by reducing data into a few biologically meaningful co-expression modules, WGCNA allows for direct association analysis with clinical and biomarker variables, thus allowing direct delineation of causative disease pathways. The validity of WGCNA is demonstrated by the reproducible and biologically meaningful results in several other applications and diseases [20-24].

Another highly useful application of microarray data is to identify disease mechanisms that are common between neurologic conditions. Studies of transcriptomic changes have been vital in elucidating the pathogenesis of neurodegenerative conditions such as Alzheimer's disease (AD )[25-27]. Utilizing such data, Miller et al. employed WGCNA to explore commonalities and differences between normal aging and pathological aging (i.e. AD) [28], resulting in the identification of biologically relevant modules conserved between $\mathrm{AD}$ and aging that included mitochondrial processes and synaptic plasticity. In the context of HAND, identifying biological pathways common to Alzheimer's disease and other neurological conditions could open the door to employing readily available pharmaceutical treatments in those with HIV.

In this paper we describe two studies. In Study 1, we extended the findings of Gelman et al. [11] in a number of ways. First, we examined the relationship between gene expression and two clinically-relevant variables: HIV-related neurocognitive impairment (regardless of HIVE status) and CNS penetration effectiveness [29] of antiretroviral drug regimens. We focused on neurocognitive impairment as this is a more continuous phenotype, as compared to neuropathological diagnosis. We also chose to examine CPE as the effect of highly penetrant regimens upon neurobiological functioning remains uncertain. We utilized both standard differential expression and WGCNA to identify biologically relevant pathways and modules associated with these clinical variables. We also utilized WGCNA to identify co-expression module differences across four clinically and/or neuropathologically distinct groups: HIV-seronegative, HIV + without HAND or HIVE, HAND without HIVE, and HAND and HIVE. We hypothesized that WGCNA would allow further and valuable interpretation of previously evaluated microarray data, and that biologically-relevant pathways and modules associated with clinical variables would be identified. In Study 2, we elucidated transcriptional commonalities and differences in neurocognitive impairment among HIV and
AD. We hypothesized that both diseases would involve common genes and pathways associated with neurocognitive impairment.

\section{Methods}

Study 1: Identifying transcriptome networks associated with neurocognitive impairment and CNS penetration effectiveness of antiretroviral regimen using both standard differential gene expression analysis and WGCNA

\section{Subject information/data acquisition}

Data were obtained from the National NeuroAIDS Tissue Consortium [30], as described previously [11]. The National NeuroAIDS Tissue Consortium consists of four study sites, in New York City (PI - Susan Morgello, M.D.), Los Angeles (PI - Elyse Singer, M.D.), San Diego (PI - Igor Grant, M.D.), and Galveston (PI - Benjamin Gelman, M. D., Ph.D.). Studies were conducted in accordance with human subject protection protocols as approved by the Institutional Review Boards at the respective sites. Written consent was obtained for subjects. Subject assessment procedures, and specimen and RNA processing were previously described [11]. In the original study, there were 24 cases divided into 4 groups according to criteria described below: Group A $(\mathrm{N}=6)$ : HIV uninfected with no neuropathological abnormalities at autopsy; Group $\mathrm{B}(\mathrm{N}=6)$ : $\mathrm{HIV}+$ neurocognitively normal with no neuropathology; Group C (N = 7) HIV + with severe HAND (defined below) with no HIVE or substantial neuropathological defect; Group D $(\mathrm{N}=5) \mathrm{HIV}$ + with HAND and HIVE. All HIV cases were evaluated within six months of death. HIV status was determined via enzyme-linked immunosorbent or polymerase chain reaction assay using blood collected pre-mortem. HIVE was diagnosed via post-mortem neuropathological examination. HAND status was determined via the Global Clinical Rating (GCR). The GCR is a summary score based on an individual's performance across a battery of neurocognitive tests. A GCR score of 1-4 indicated performance ranging from above average to normal; GCR of 5-9 indicated progressively severe impairment.

For the current study, 21 of the 24 cases were used: two cases from group B were removed due to poor quality RNA and one case from group D was removed due to presence of brain-related opportunistic infection upon neuropathological examination. Specifically, sample WM-A6-06, and all three samples from subjects B5, $\mathrm{B} 6$, and D5 were removed. RNA was processed using the Affymetrix $^{\circledR}$ gene array platform (human 133 plus 2.0). Three brain regions were examined: frontal neocortex (FC), neostriatum (BG), and frontal white matter (WM). Table 1 displays pre-mortem participant characteristics and post-mortem interval (PMI: time between death and removal of brain). In Study 1, the grouping method employed by Gelman et al. [11] was used only for the 
Table 1 Group characteristics from Gelman et al., 2012 [70]

\begin{tabular}{ccccccc}
\hline Group (N) & HIV status & $\begin{array}{c}\text { Neurocognitive } \\
\text { Impairment (GCR) }\end{array}$ & HIVE & CPE* & Age (years) & PMI (hours) \\
\hline A (6) & Negative & No (NA) & NA & NA & $50 \pm 10$ & $19 \pm 5.1$ \\
B (4) & Positive & No $(2.8 \pm 1.3)$ & No & $2.1 \pm 0.9$ & $50 \pm 6.5$ & $11 \pm 8.1$ \\
C (7) & Positive & Yes (7.1 \pm 0.7$)$ & No & $1.3 \pm 2$ & $44 \pm 9.8$ & $7.2 \pm 2.1$ \\
D (4) & Positive & Yes (8.3 \pm 1.7$)$ & Yes & $1.8 \pm 0.3$ & $44 \pm 10$ & $11 \pm 4.8$ \\
\hline
\end{tabular}

* Note that this grouping schema was used only on one analysis in Study1.

* CNS Penetration Effectiveness. Higher values indicate greater penetration of antiretroviral medications into brain.

initial WGCNA to determine if this interrogative method was of added value. For purposes of this study, those with scores above 6 were considered to have HAND. This level of neurocognitive impairment is consistent with severe HAND, or HIV-associated dementia [1].

Study 1 also included correlation of gene expression with the clinical variables described next. These data were obtained within six months prior to death.

CNS penetration effectiveness (CPE) The reported effects of antiretroviral medications upon neurocognitive functioning ranges from beneficial [31,32] to detrimental [33]. As such, we sought to determine the impact of antiretroviral regimen on gene expression. We employed the CPE, a score that is based on the pharmacokinetic and pharmacodynamic characteristics of antiretroviral medications [29]. CPE scores for the last known regimen were calculated. Higher scores indicate a regimen with increased penetration of the blood brain barrier and therefore putatively greater impact on neurobiological activity.

Neurocognitive impairment (NCI) NCI is the key feature of HAND and is often association with postmortem HIVE. We sought to determine transcriptional correlates of neurocognitive functioning, as reflected by the GCR (described above) in HIV + cases only. Used as a continuous variable in the current paper, higher scores indicate greater impairment.

\section{Statistical analyses}

Data preprocessing Gene array data was received in the form of Affymetrix .cel files. These files were then read into $\mathrm{R}$ and preprocessed using the espresso function and the MAS5 method of preprocessing. We chose MAS5 based on a study by Lim et al. [34], which found that MAS5 provides the most faithful cellular network reconstruction of the four commonly used normalization procedures (MAS5, RMA, GCRMA and Li-Wong). Our unbiased array outlier detection method considered metrics measuring RNA quality and low inter-array correlations. First, we calculated the un-normalized inter-array correlation using the Pearson correlation [35]. Hierarchical clustering based on the inter-array correlations revealed seven outlying arrays (all samples from two subjects in group B, and the WM sample from one subject in group A). The majority of these samples also were found to have poor quality RNA during the quality control step, suggesting that this outlier removal method based on hierarchical clustering is reasonable. We also removed all samples from one individual in group D due to the presence of confounding CNS co-infections (Cytomegalovirus and Papovavirus). Quantile normalization was then performed on the remaining data. Probe sets that were called "absent" in $>90 \%$ of the samples by MAS5 preprocessing were excluded from further consideration. In order to decrease computational constraints and facilitate between-study comparisons, the function collapseRows in the WGCNA library was used to select a single probe set for each gene. Our studies show that the most reproducible representative probe set is the one with the highest average expression across samples [36]. Probe sets without associated gene symbols were omitted. In summary, each gene symbol was represented by a single probe set.

\section{Differential expression analyses}

The relationship between each gene and the two clinical variables (NCI and $\mathrm{CPE}$ ) were assessed across three brain regions (FC, WM, and BG) using Pearson correlation. The Pearson correlation test is appropriate since it only assumes that one of the quantitative variables (here gene expression) follows a normal distribution. Results of these differential expression analyses were used in three ways. First, enrichment analyses were performed on all differentially expressed genes ( $\mathrm{p}<0.05$ in all cases) using Expression Analysis Systematic Explorer (EASE) [37]. EASE functionally categorizes gene lists based on enrichment for all levels of the gene ontology (GO), Kyoto Encyclopedia of Genes and Genomes (KEGG), or SwissProt terms, and returns an EASE score (similar to a p-value) for assessing significance. Second, the trait-gene relationship values (i.e., correlations or T-values) for all genes were retained and converted into a color vectors for visual assessment of disease-gene relationships in the network analysis. In addition to NCI and CPE, color vectors for HIV and HIVE status were produced. Finally, to further explore network 
functioning of genes implicated in NCI and CPE, genes with the highest correlations were entered into GNCPro (http://GNCPro.sabiosciences.com) [38] to understand additional biological relationships. GNCPro, free online software developed and maintained by SABiosciences, is an in silico research tool for collating gene and pathway interactions. GNCPro integrates collective biological knowledge through text mining, data mining, data acquisition and computational prediction. The interactions among a group of genes are represented graphically and are interactive. Gene co-expression relationships are designated as edges and the genes and proteins are designated as nodes. Gene co-expression relationships are calculated as previously described [39] and Shannon's Entropy formula is used to calculate human gene tissue expression profiles [40]. Gene groups are identified by categories including expression, interaction, modification, and regulation (http://GNCPro.sabiosciences.com). In addition, it should be noted that the GNCPro program has an upper limit of 100 genes that can be shown in any network analysis, including the input genes.

\section{Weighted gene co-expression network analysis}

Here we employ for the first time WGCNA to the analysis of HIV brain transcriptome data. The WGCNA started out from 14099 genes assayed, identifies modules of co-expressed genes, and relates these modules to clinical variables and gene ontology information $[13,15,41]$. Because gene modules may correspond to biological pathways, focusing the analysis on modules (and their highly connected intramodular hub genes) amounts to a biologically meaningful data reduction scheme. Highly correlated module genes are represented and summarized by their first principal component (referred to as the module eigengene, or ME [42]). The ME is used to define measures of module membership which quantify how close a gene is to a given module. Module membership measures allow one to annotate all genes on the array and to screen for disease related intramodular hub genes $[15,43,44]$. As described below, we use functional enrichment analysis with regard to known gene ontologies to understand the biological significance of the ME and to identify putative disease pathways.

WGCNA was performed separately for each of the three brain regions using the most highly expressed probe for each gene present in at least six samples, as previously described $[15,35,41]$. In short, for each analysis the Pearson correlations between all genes across all relevant samples were calculated. We calculated a signed-weighted co-expression adjacency matrix as follows:

$$
\text { adjacency }=[(\text { correlation }+1) / 2]^{12}
$$

This allowed us to keep track of the direction of the correlation. Note that a correlation of -1 and +1 lead to an adjacency value of 0 and 1 , respectively. Recent studies have shown that signed co-expression networks can be superior when it comes to detecting small modules [21]. The power 12 is the default soft threshold parameter for constructing a signed weighted network [21,41]. Topological overlap (TO), a more biologically meaningful measure of node interconnectedness (similarity), was then calculated as described previously $[35,41,45,46]$. Next, genes were hierarchically clustered using $1-\mathrm{TO}$ as the distance measure and modules were determined by using a dynamic tree-cutting algorithm [47].

To enhance reader friendliness the module labels of different data sets were relabeled using the WGCNA function matchLabels. This function compares the genes comprising each module in both data sets using a hypergeometric test, then relabels modules in the second data set so that modules with a significant number of overlapping genes between data sets will have the same label. For example, if the Blue module in the second data set corresponds to the Turquoise module in the first data set, then we relabeled the Blue module as Turquoise module. Thus, modules with the same label have a significant number of overlapping genes, but not identical genes, and modules with labels unique to a single data set were not recapitulated in the other data sets.

The expression profiles of genes inside a co-expression module were summarized by the ME, which is the first principal component. Note that the ME is the mathematically optimal summary of the module expression profiles since it captures the maximum amount of variation $[42,48]$. In the current study, the MEs were used in two analyses. First, they were compared across groups A, B, C, and D using ANOVA. Second, they were correlated to both of the clinical variables (NCI and CPE) to identify trait related modules. To further enhance data interpretation, we used EASE to characterize modules (as described above), and also used the function userListEnrichment from the WGCNA library to find enrichment for cell type markers and other brain-related categories. Additional details and related software tutorials can be found at our webpage: http://www.genetics.ucla. edu/labs/horvath/CoexpressionNetwork/.

\section{Study 2: differential gene expression and enrichment analysis to determine common pathways associated with neurocognitive impairment in HIV and Alzheimer's disease}

\section{Patient groups}

All HIV + cases (Groups B, C, and D, as described above) were used. Data for Alzheimer's (AD) cases was produced in a previous study (Blalock et al., 2004) [25] and available on the Gene Expression Omnibus. In that 
study, AD cases were clinically evaluated and their diagnosis was confirmed at autopsy. After removing 3 outliers (see [28]), there were 8 controls, 6 cases with incipient (mild) dementia, 8 with moderate dementia, and 6 with severe dementia. Dementia severity was determined primarily via pre-mortem neurocognitive testing. Gene expression data for both studies were profiled using Affymetrix $^{\circledR}$ gene array platforms (HG-U133A).

\section{Primary clinical outcomes}

Study 2 included correlation of gene expression with neurocognitive impairment. As in Study 1, neurocognitive impairment was determined using the GCR in $\mathrm{HIV}+$ cases, as described above. In AD cases, the Mini Mental Status Exam, or MMSE [49], was used. The MMSE is a widely used neurocognitive screening measure. Scores range from 0-30, with lower scores indicating greater impairment.

\section{Statistical analysis}

To assess the transcriptional similarities between NCI associated with HIV and $\mathrm{AD}$, gene microarray data from FC and BG of the 15 HIV+ brains (Groups B, C, and D described above) were compared to that of hippocampus of 30 brains obtained from individuals from the Blalock et al. study, including 8 neurocognitively normal controls and 22 with autopsy-confirmed AD [25].

First, we chose a single probe for each gene in the AD analysis using collapseRows as with these data, omitting all genes except the ones common to both analyses (total common genes $=8167$ ) [36]. Second, we calculated the correlation between transcription level of each of these genes and the MMSE score in the AD data for comparison with the correlations between the respective genes and GCR scores in the HIV + group. We then plotted each of these pairs of correlations as a point on a graph in order to assess to what extent impairment genes in HAND are also impairment genes in AD. We define "impairment genes" as genes whose expression either increases (upper right of plots; $\mathrm{R}>0.25$ ) or decreases (lower left of plots; $\mathrm{R}<-0.25$ ) with impairment in the hippocampus of $\mathrm{AD}$ subjects, as well as both the $B G$ and FC of HAND subjects. We then conducted enrichment analysis on significant genes. In addition, we assessed which of the modules in the WGCNA of HIV + brains were also enriched for AD-related impairment genes by comparing the number of genes in the Blalock study that were correlated with MMSE score with the number expected by chance using a hypergeometric test.

An overview of both studies and associated analyses are depicted in Figure 1.

\section{Results}

Study 1: Standard differential gene expression analysis of clinical variables

The relationship between individual gene expression and both clinical variables, CPE and NCI, are described here. While no genes achieve significance after correcting for multiple comparisons, we still present the top genes as potential genes of interest for future studies, but note that many are expected to be false positives. The fact that these results are not significant after adjusting for multiple comparisons highlights a major pitfall of standard differential expression analysis. In contrast, module based analyses provided by WGCNA largely circumvent the multiple comparison problem as shown below.

\section{CPE}

All genes with an absolute correlation co-efficient (i.e., positive or negative) value of .75 or greater are listed in Table 2. Correlations are between absolute gene expression and CPE score. Additional correlations are provided in the Supplemental Data [Additional file 1 - Gene Correlations with $\mathrm{NCI}$ and CPE.xls].

\section{$\mathrm{NCl}$}

Genes with absolute correlation coefficients of greater than .75 are listed in Table 3. Additional results of this analysis are provided in the Supplemental Data [Additional file 1 Gene Correlations with NCI and CPE.xls].

\section{Detailed enrichment analysis of top genes related to clinical variables}

To further understand gene expression pathways related to HIV-related brain dysfunction, we examined enriched GO categories associated with CPE and NCI in all three brain region based on genes identified in the differential expression analysis. After correcting for multiple comparisons, no categories were found to be associated with CPE. The results of the NCI analysis are shown in Table 4. After correcting for multiple comparisons, gene pathways involved in mitochondrial functioning, mitotic cell cycle, DNA repair, proteasome complex, and nucleus were downregulated in the FC. No significant downregulated pathways were found in the BG or WM. Upregulated pathways were more widely distributed across the brain, with some overlap between regions. For example, transcription regulation was upregulated in both the FC and WM, whereas the genes on Homo Sapiens chromosome 19 were enriched in the BG and WM. Other pathways, shown in Table 4, were significant in single regions.

To further interrogate these data, and since we were unable to find significant enrichments for CPE using traditional GO enrichment analysis, we expanded our results into the known literature using GNCPro [38], as described above. Genes listed in Tables 2 \& 3 were entered into 


\begin{tabular}{|c|c|c|c|}
\hline Study & Analysis & Samples & Statistical Approach \\
\hline \multirow{4}{*}{$\begin{array}{l}1 \text { - Description: To utilize } \\
\text { standard differential gene } \\
\text { expression analysis and } \\
\text { WGCNA to explore } \\
\text { transcriptome changes } \\
\text { associated with } \\
\text { neurocognitive impairment } \\
\text { and antiretroviral regimen, } \\
\text { and to further interrogate } \\
\text { extant transcriptome data } \\
\text { using WGCNA }\end{array}$} & $\begin{array}{l}\text { Differential gene expression } \\
\text { analysis of } \mathrm{NCl} \text { and } \mathrm{CPE}\end{array}$ & $15 \mathrm{HIV}+$ brains & $\begin{array}{l}\text { Pearson Correlation of individual gene expression } \\
\text { levels with } \mathrm{NCl} \text { (GDS score) and CPE. Those with highest } \\
\text { correlations ( }>.70 \text { or <-.70) were then examined using } \\
\text { GNCPro, a bioinformatics tool. }\end{array}$ \\
\hline & $\begin{array}{l}\text { Enrichment analysis of genes } \\
\text { significantly correlated with } \\
\mathrm{NCl} \text { or } \mathrm{CPE}\end{array}$ & $15 \mathrm{HIV}+$ brains & $\begin{array}{l}\text { Enrichment analyses were performed on all } \\
\text { differentially expressed genes }(p<0.05) \text { using } \\
\text { Expression Analysis Systematic Explorer [33]. }\end{array}$ \\
\hline & $\begin{array}{l}\text { WGCNA of groups previously } \\
\text { defined by Gelman et al, } \\
2012\end{array}$ & $\begin{array}{l}6 \text { HIV- } \\
4 \text { HIV+ } \\
7 \text { HAND } \\
4 \text { HAND/HIVE }\end{array}$ & $\begin{array}{l}\text { ANOVA used to compare module eigengenes across } \\
\text { four groups }\end{array}$ \\
\hline & WGCNA of $\mathrm{NCl}$ and CPE & $15 \mathrm{HIV}+$ brains & $\begin{array}{l}\text { Correlated modules discovered through WGCNA with } \\
\mathrm{NCl} \text { and } \mathrm{CPE}\end{array}$ \\
\hline $\begin{array}{l}\text { 2-Description: To identify } \\
\text { genes and pathways } \\
\text { associated with NCl in both } \\
\text { HIV and Alzheimer's disease. }\end{array}$ & $\begin{array}{l}\text { Identify genes that are } \\
\text { commonly associated with } \\
\mathrm{NCl} \text { in HIV and Alzheimer's } \\
\text { disease }\end{array}$ & $\begin{array}{l}15 \text { HIV+ brains } \\
8 \text { HIV-/normal controls } \\
20 \text { HIV-/AD }\end{array}$ & $\begin{array}{l}\text { In each sample (HIV+ and control/AD), correlated all } \\
\text { gene probes with } N C l \text {. Impairment genes were defined } \\
\text { as those whose expression either increased }(R>0.25) \text { or } \\
\text { decreased }(R<-0.25) \text { with impairment. }\end{array}$ \\
\hline
\end{tabular}

Figure 1 Overview of studies and analyses, in the order that they appear in the results.

Table 2 Top correlations between genes and CPE in each brain region

\begin{tabular}{|c|c|c|c|c|c|c|c|c|}
\hline \multicolumn{3}{|c|}{ Frontal cortex } & \multicolumn{3}{|c|}{ Basal ganglia } & \multicolumn{3}{|l|}{ White matter } \\
\hline Gene name & $\mathbf{R}$ & P-value* & Gene name & $\mathbf{R}$ & P-value* & Gene name & $\mathbf{R}$ & P-value* \\
\hline WBSCR16 & 0.82 & 0.0003 & LOC730496 & 0.82 & 0.0003 & TMEM57 & -0.81 & 0.0006 \\
\hline MYST1 & 0.82 & 0.0004 & CA13 & 0.82 & 0.0003 & NFIC & 0.80 & 0.0006 \\
\hline RPS6KB2 & 0.82 & 0.0004 & CLEC14A & 0.81 & 0.0004 & KIAA0515 & 0.79 & 0.0007 \\
\hline ZNF26 & 0.81 & 0.0004 & C18orf17 & 0.78 & 0.0010 & CIDEB & 0.79 & 0.0007 \\
\hline DCAKD & -0.79 & 0.0008 & OSBPL6 & -0.77 & 0.0012 & $\mathrm{RDH} 11$ & -0.79 & 0.0008 \\
\hline LYPLA2 & 0.78 & 0.0009 & MRAS & 0.77 & 0.0012 & HMHB1 & -0.79 & 0.0009 \\
\hline NME3 & 0.78 & 0.0010 & SSR3 & 0.77 & 0.0012 & VPS13D & 0.78 & 0.0011 \\
\hline SLC10A2 & 0.76 & 0.0015 & FUT2 & 0.77 & 0.0012 & TAF5L & 0.77 & 0.0012 \\
\hline \multirow[t]{9}{*}{ TRIM31 } & 0.76 & 0.0015 & EHHADH & 0.76 & 0.0014 & TNPO3 & 0.77 & 0.0014 \\
\hline & & & MOSPD1 & -0.76 & 0.0015 & FLJ45803 & 0.76 & 0.0017 \\
\hline & & & SIKE & 0.76 & 0.0016 & C6orf113 & -0.76 & 0.0018 \\
\hline & & & TMEM67 & -0.76 & 0.0016 & C19orf43 & 0.75 & 0.0018 \\
\hline & & & LASS4 & 0.76 & 0.0017 & SH3GLP3 & 0.75 & 0.0018 \\
\hline & & & AGPAT6 & 0.76 & 0.0017 & & & \\
\hline & & & CCDC100 & 0.76 & 0.0017 & & & \\
\hline & & & ACVR2B & 0.75 & 0.0018 & & & \\
\hline & & & SREBF2 & 0.75 & 0.0018 & & & \\
\hline
\end{tabular}

* p-values shown are not corrected for multiple comparisons. 
Table 3 Top correlations between genes and $\mathrm{NCl}$ in each brain region

\begin{tabular}{|c|c|c|c|c|c|c|c|c|}
\hline \multicolumn{3}{|c|}{ Frontal cortex } & \multicolumn{3}{|l|}{ Basal ganglia } & \multicolumn{3}{|c|}{ White matter } \\
\hline Gene name & $\mathbf{R}$ & P-value* & Gene name & $\mathbf{R}$ & P-value* & Gene name & $\mathbf{R}$ & P-value* \\
\hline GINS1 & -0.80 & 0.0004 & TP53BP2 & 0.85 & 0.00006 & GNAZ & 0.84 & 0.00009 \\
\hline ACADM & 0.77 & 0.0007 & COQ10A & 0.82 & 0.0002 & NIPSNAP3A & -0.82 & 0.0002 \\
\hline ATAD3B & 0.76 & 0.0009 & GINS2 & -0.81 & 0.0003 & ID2 & -0.82 & 0.0002 \\
\hline C8orf48 & 0.76 & 0.0011 & PCDHB6 & -0.79 & 0.0005 & ADO & 0.80 & 0.0003 \\
\hline EFTUD2 & -0.76 & 0.0011 & $\mathrm{RHOJ}$ & 0.78 & 0.0006 & CHADL & 0.79 & 0.0005 \\
\hline \multirow[t]{7}{*}{ CLUAP1 } & -0.75 & 0.0013 & LOC550631 & -0.78 & 0.0006 & GRK6 & 0.78 & 0.0006 \\
\hline & & & CADM1 & 0.78 & 0.0007 & FBXL13 & -0.78 & 0.0006 \\
\hline & & & $\mathrm{FECH}$ & -0.76 & 0.001 & ARHGAP22 & 0.77 & 0.0007 \\
\hline & & & SFRS1 & 0.75 & 0.0011 & CHST12 & 0.77 & 0.0008 \\
\hline & & & & & & DAP & -0.76 & 0.0009 \\
\hline & & & & & & PASK & -0.76 & 0.0010 \\
\hline & & & & & & C9orf142 & 0.76 & 0.0011 \\
\hline
\end{tabular}

* p-values shown are not corrected for multiple comparisons.

GNCPro allowing visualization of various types of interactions among the identified genes. We include only diagrams of the WM for both CPE and NCI (Figure 2). We chose WM based on the current available literature, which indicates that antiretroviral regimen has the most conspicuous metabolic effects within this region [50]. (Diagrams for remaining regions are available as Supplemental material). For CPE, co-expression connectivity was the most prevalent of the several types of connectivity identifiable by GNCpro. We observe high connectivity of transportin 3 (TNPO3). TNPO3 is necessary for full integration of HIV-1 into the host DNA $[51,52]$. Counter intuitively, expression of this gene was positively correlated with CPE in the WM.

Table 4 Enriched GO categories for genes related to neurocognitive impairment

\begin{tabular}{llll}
\hline Down with impairment & $\begin{array}{l}\text { Frontal } \\
\text { cortex }\end{array}$ & $\begin{array}{l}\text { Basal } \\
\text { ganglia }\end{array}$ & $\begin{array}{l}\text { White } \\
\text { matter }\end{array}$ \\
\hline Mitochondrion & $6.86 \mathrm{E}-6$ & NS & NS \\
Mitotic Cell Cycle & $1.63 \mathrm{E}-04$ & NS & NS \\
DNA Repair & $4.86 \mathrm{E}-04$ & NS & NS \\
Proteasome Complex & $5.06 \mathrm{E}-04$ & NS & NS \\
(sensu Eukarya) & & & NS \\
Nucleus & $1.10 \mathrm{E}-03$ & NS & White \\
Up with Impairment & Frontal & Basal & Matter \\
Transcription Regulation & Cortex & Ganglia & $2.10 \mathrm{E}-03$ \\
Receptor Activity & $5.49 \mathrm{E}-06$ & NS & NS \\
DNA Binding & $3.39 \mathrm{E}-04$ & NS & NS \\
Protein Kinase Activity & $1.34 \mathrm{E}-03$ & NS & NS \\
Homo Sapiens 19 & NS & $7.13 \mathrm{E}-04$ & $2.27 \mathrm{E}-03$ \\
Chondroitin/Heparin & NS & $1.18 \mathrm{E}-02$ & $8.37 \mathrm{E}-05$ \\
Sulfate Biosynthesis & NS & NS & \\
\hline & & & \\
\hline
\end{tabular}

Also observed to have high co-expression connectivity in the WM, although of less clear relation to CPE, were retinol dehydrogenase 11 (RDH11), vacuolar protein sorting 13 (VPS13D), and nuclear factor I/C (NFIC). For NCI, the most common types of connectivity indicated through GNCPro were protein-protein interactions and physical interaction. However, for one gene, Inhibitor of DNA Binding (ID2), there was a high diversity of interactions. Another apparently relevant gene showing modest connectivity is death-associated protein (DAP). Both ID2 and DAP were negatively correlated with NCI. A third gene, G protein-coupled receptor kinase 6 (GRK6), was positively correlated with NCI. A final highly connected gene within this network, of unclear importance, was guanine nucleotide-binding protein - alpha $\mathrm{Z}$ polypeptide (GNAZ).

\section{Weighted gene co-expression network analysis}

We applied WGCNA to probes detected in at least 6 samples, as reported by the Affymetrix cel files, including only a single probe for each gene. Hierarchical clustering led to the identification of several co-expression modules, ranging in number and size between the three regions. To assess the robustness of the co-expression module definition, we replicated module detection across all three brain regions. We find that of the 11, 13, and 14 modules in the FC, BG, and WM networks, respectively, six have correlates in all three networks and several more span two networks (Figure 3). Furthermore, when we use more sensitive module preservation statistics [17], we find that all of the common modules have strong preservation, except for the brown module (8), which has moderate preservation, and the red module (6), which is preserved well between FC and BG, but not as well in WM. 


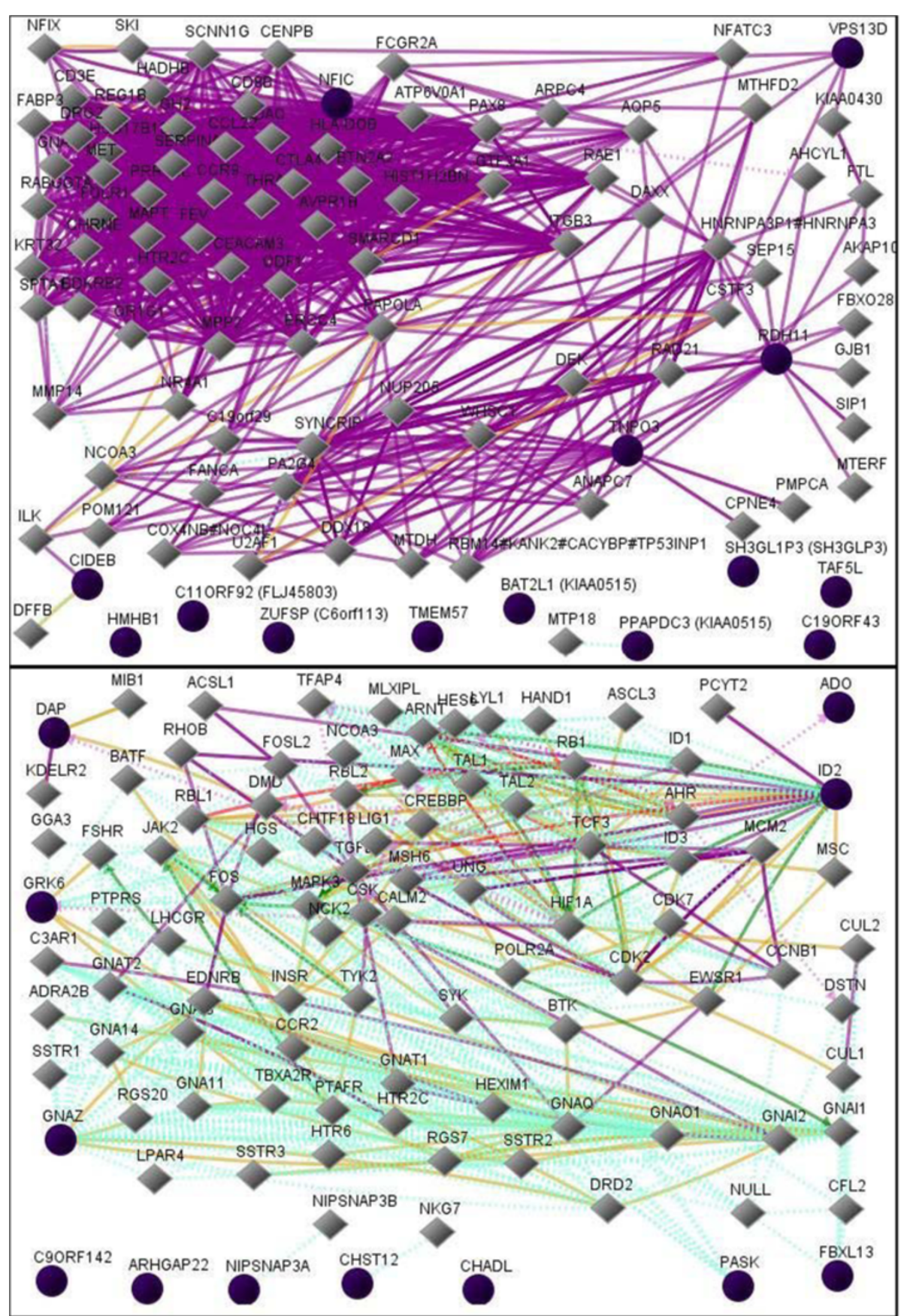

Figure 2 Network diagram of CPE-related genes (top panel) and NCl-related genes (bottom panel) in white matter. Input genes from Table 2 are indicated by solid black circles. The diamond-shapes are neighboring genes that are identified by literature-based associations. There are various types of interactions among the genes represented as lines and dotted lines in color as follows: Down-regulation - red; Up-regulation - green; Regulation - grey; Co-expression - purple; Physical Interaction - brown; Predicted Protein Interaction - dotted aquamarine; Predicted Transcription Factor Regulation - dotted brown.

Differential module eigengene expression across the four groups

Our module definition was solely based on the gene expression levels in brain tissue without consideration of HIV disease severity. In other words, modules were derived from all sample transcriptomes, regardless of group. To incorporate clinical and disease variables into the network analysis, WGCNA makes use of suitably defined gene significance measure. Here we defined the gene significance measure using ANOVA for testing differential module expression (as captured by the module eigengene) between the four groups. Thus, a large 


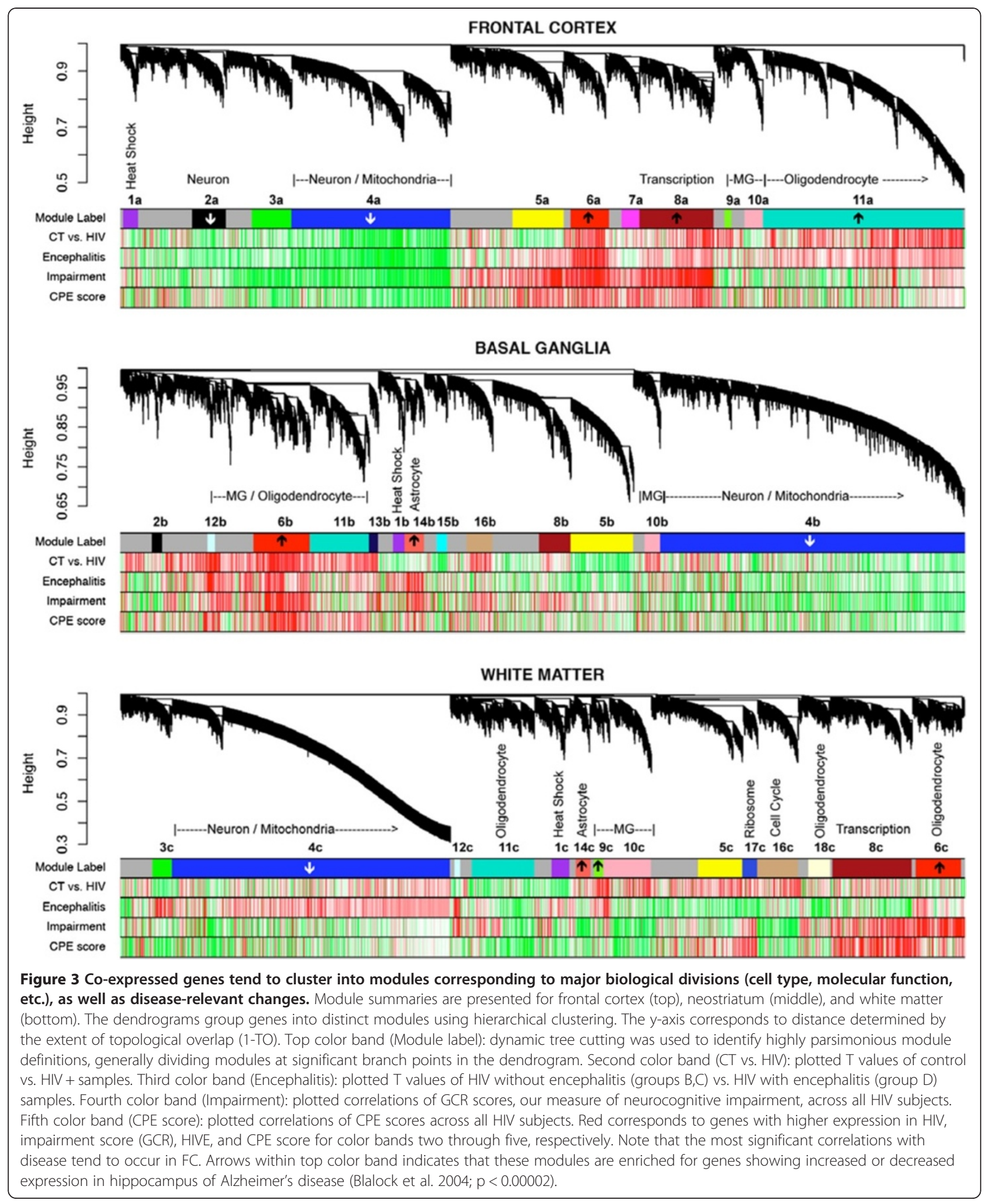


absolute value of the gene significance measure corresponds to a small 2-sided p-value. Note that we discuss only those modules that reached a non-adjusted significance threshold of $\mathrm{p}<0.05$, which represent trends in the data relating modules to clinical variables. Additional module information, including hub genes (i.e., correlations between individual genes and $\mathrm{ME}$ ) and gene category enrichments (e.g., Swissprot, GO) for each module, is available in the Supplement Material [Additional file 2 Module and User Enrichment - All Modules.xls].

In the frontal cortex, the Red (Figure 3, Color band 6a), Blue (4a), and Turquoise (11a) modules showed trends towards differential expression across the four clinical groups (Figure 4, Panel A). The Red module (6a), here enriched with genes involved in transcription and DNA binding, as well as oligodendrocyte-related functioning, shows increased expression in the HIVE group ( $\mathrm{p}=.033$ ). The Blue module (4a) showed decreasing expression as disease severity increases $(p=.031$;
Figure 4, Panel A). Top GO and Swissprot categories for the Blue module were hydrogen ion transporter activity, monovalent inorganic cation transporter activity, mitochondrion, and transporter activity. Finally, the Turquoise module (11a) also showed increased expression in the HIVE group $(\mathrm{p}=.042)$, and included the following GO and Swissprot categories: lysosome, lytic vacuole, glycosidase, antigen presentation, and interferon induction.

Within the white matter, the Light Cyan module (12c) showed a trend towards differential expression across the four clinical groups $(\mathrm{p}=.011$; Figure 4, Panel B). The HIVE group demonstrated the highest expression level of this module. Interestingly, the HIV-seronegative group had higher expression than the other two HIV + groups. Top GO and KEGG pathways were hydrogen-transporting two-sector ATPase activity, carbohydrate metabolism, MHC-interacting protein, intracellular, and cell adhesion.

Finally, we examined modules in the basal ganglia network across all four clinical groups. The Light Cyan

\section{A}

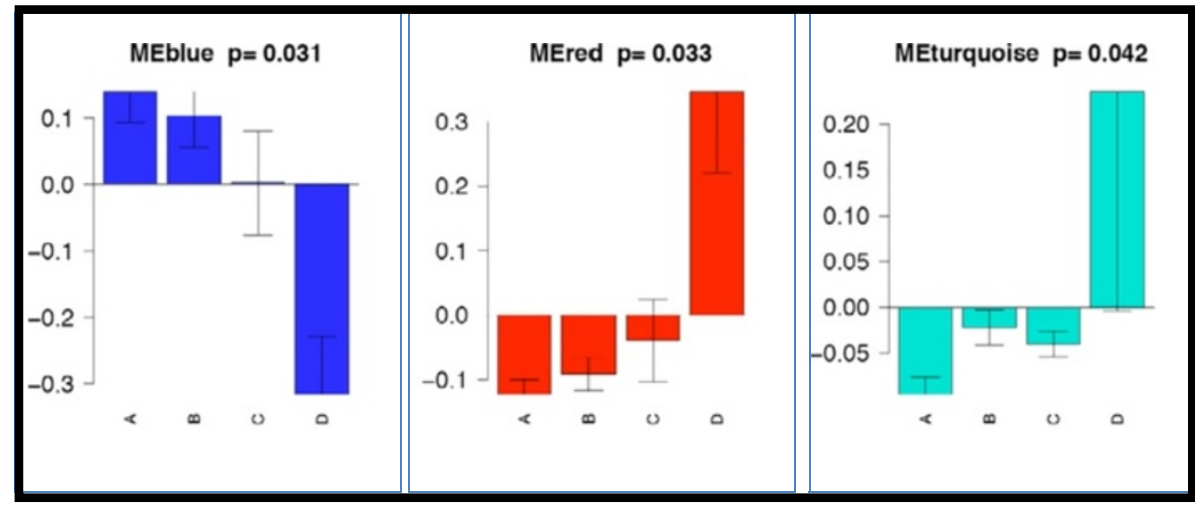

B
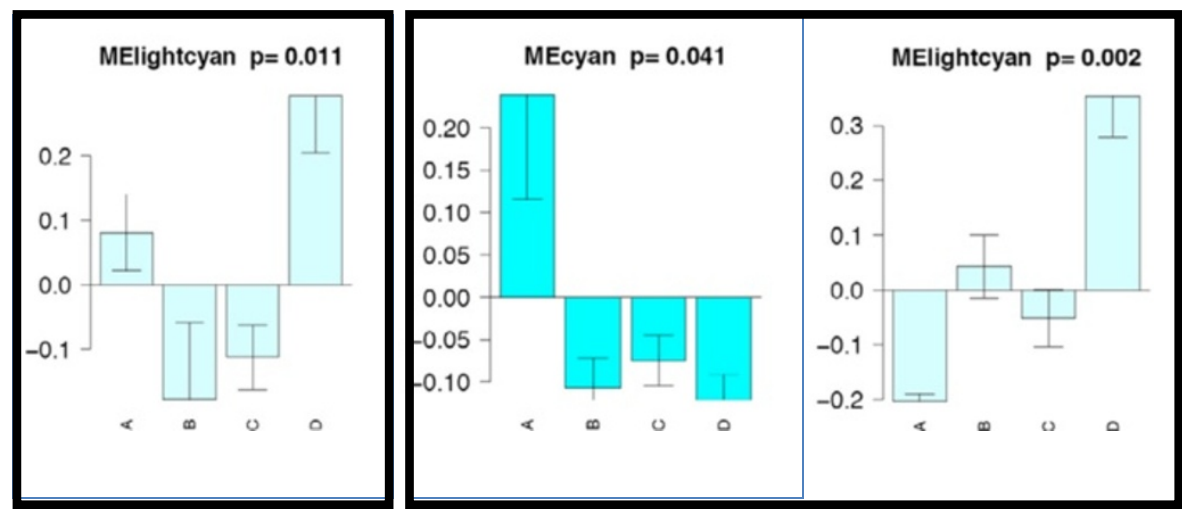

Figure 4 Modules show different expression patterns across groups. (A) The Blue, Red, and Turquoise modules from the frontal cortex show significant (Kruskal Wallis test $\mathrm{p}<0.05$ ) differences between groups. The $\mathrm{Y}$ axis corresponds to module eigengene expression. (B) The Light Cyan module shows increased expression with encephalitis in frontal white matter. In (C), the Cyan and Light Cyan modules show differential expression across groups in basal ganglia. 
(Figure 3, Color ban 12b) showed between-group differences of $\mathrm{p}=0.002$, which was significant after correcting for multiple comparisons. The Cyan (15b) module showed a trend $(p=0.041)$. For the Light Cyan module, the HIVE group (Group D) had higher expression than the other two HIV + groups (Groups B \& C), while the HIV-seronegative group (Group A) had the lowest expression (Figure 4, Panel C). Enrichment analysis of the Light Cyan module revealed the following top GO and Swissprot terms: immune response, response to biotic stimulus, defense response, and interferon induction. The top GO term for the Cyan module was transferase activity. The HIV-seronegative group had higher expression of the Cyan module than all three HIV + groups.

\section{Correlations between module eigengenes and clinical variables}

Above we described differential expression analysis correlations between individual genes and the clinical variables (CPE or NCI). Here, we correlated module eigengenes with the clinical variables. The two approaches differ in that the differential expression analysis employs enrichment analysis as a method to interpret differentially expressed genes, whereas WGCNA identifies biological meaningful networks before examining their association with $\mathrm{CPE}$ and NCI. As such, WGCNA makes significantly fewer comparisons, thereby reducing the chance of Type I error. Here we report as trends those comparisons that reached a .05 threshold.

\section{CPE}

None of the modules were significantly correlated with CPE score in any of the brain regions.

\section{$\mathrm{NCl}$}

In the FC, the Brown (8a) and Yellow (5a) modules showed a trend towards correlation with NCI (Figure 5,
Panel A). The Brown module was largely enriched with transcription genes, whereas the Yellow module was enriched for glycoprotein, signal and extracellular gene categories. Enrichment categories are listed in the Supplemental Material. The Red module (6a), largely enriched with transcription and DNA-binding genes, as well as oligodendrocyte functioning, also shows a notable trend $(\mathrm{R}=.51, p=.052)$. In all three instances, higher module expression correlated with greater NCI. Complete enrichment information for the $\mathrm{FC}$ and other brain regions is included as a Supplemental Table [Additional file 3 Module Enrichment NCI Only.xls].

In the WM, the Red module (6c), here enriched for oligodendrocyte marker genes, showed a trend towards correlation with NCI ( $\mathrm{R}=0.53, \mathrm{p}=0.042$; Figure 5, Panel B). Higher module expression correlated with greater NCI.

No significant correlations or trends between module expression and NCI among the $\mathrm{HIV}+$ cases were found in the BG.

\section{Study 2: comparison of HAND and Alzheimer's disease transcriptomes}

In study 2 we sought to advance understanding of common mechanisms shared by HIV and AD by identifying genes that were similarly dysregulated in both diseases. A total of 234 genes were found to be upregulated and 413 genes downregulated in both diseases. As shown in Figure 6, the correlations between each of these genes and the respective neurocognitive scores indicate modest correlation between AD and HIV. Enrichment analysis revealed that genes in which expression decreased as $\mathrm{NCI}$ increased in both AD and HIV included those involved in cytoplasm, energy pathways, mitochondrion, tricarboxylic acid cycle, transit peptide, and synaptic vesicle, along with neuronal marker genes. Conversely, expression increased with NCI in genes involved in cell differentiation,

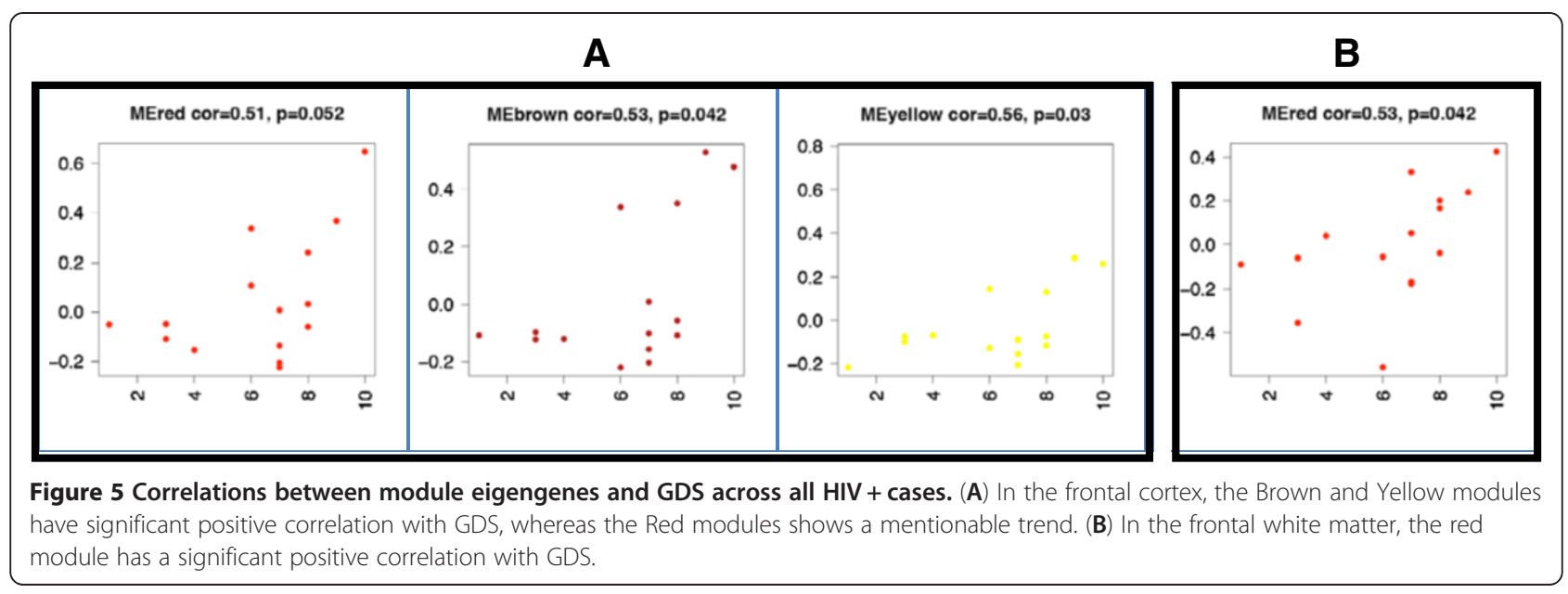


activator, repeat, cell communication, regulation of transcription, and phosphorylation, along with marker genes for astrocytes (see Table 5).

Expression changes in modules identified via WGCNA of the HIV + sample are shown in Figure 3. This is strictly for illustrative purposes, as no formal analyses were conducted to assess degree of change. Modules with arrows are enriched for genes showing increased $(\uparrow)$ or decreased $(\downarrow)$ expression in the hippocampus of AD brains.

Furthering our understanding of which specific brain cells are involved in $\mathrm{AD}$ and $\mathrm{HIV}$, results of cellular composition analysis are shown in Table 6. The analysis indicates that the impairment signature common to AD and HAND is likely marking neuronal loss/dysfunction accompanied by gliosis, or upregulation of astrocyte-mediated pathways.

Finally, we list genes that showed the strongest intramodule connectivity $(>.70$ or $<-.70)$ in both AD and HIV in Table 7. These genes can be considered to have a central role in association with NCI in both AD and HIV. For the HIV cases we included only FC and BG as these regions are more similar to the hippocampus with regards to cell types. As shown in Table 7, among the upregulated genes there was a disproportionate number involved in cancer and tumor suppression. Downregulation of transcription occurred largely in genes involved in mitochondrial functioning and also genes implicated in several neurological diseases.

\section{Discussion}

In the studies described within this paper, we employed WGCNA to further explore transcriptome changes within brain tissue of $\mathrm{HIV}+$ individuals. In addition, we directly compared transcriptome changes in brains obtained from individuals with HIV to those with Alzheimer's disease. WGCNA has many advantages over traditional methods for differential expression analysis, including a focus on co-expression patterns thereby allowing for identification of biologically-relevant modules consisting of related genes, detection of hub genes that may eventually serve as targets for therapeutic modulation, and reducing data allowing for direct association analysis with disease-related variables [20-24,54].

HAND is a common consequence of HIV infection [55]. As suggested by the results of Gelman et al. [11], there may be two distinct etiologies for HAND. The first is associated with neuropathological findings of HIVE together with high brain viral load and global upregulation of inflammatory response genes and downregulation of neuronal pathways with the FC. The second lacks the classic neuropathological findings of HIVE and is associated with relatively low brain viral load. This type also has relatively little transcriptomic dysregulation, with the exception of upregulated endothelial cell type transcripts in the BG. Overall our results, largely indicated by statistical trends rather than significant findings, recapitulate the main findings of Gelman et al. [11]. For example, both the previous and current studies found significant upregulation of pathways involved in inflammation and neuroimmunity in those with HIVE. In the current study, this was reflected in the Light Cyan (12b) and Turquoise (11a) modules in the BG and FC, respectively, and to a lesser extent the Light Cyan module in the WM (12c). Note that our analysis differed from Gelman et al. in that we did not directly compare pairs of groups (e.g., A vs. D), but rather examined all groups via ANOVA. Further, Gelman et al. performed their enrichment analysis using Ingenuity software, and probed for changes in expression of more than twofold. Conversely we utilized WGCNA, which allowed for the further analysis of these data and provided additional avenues of study based on this precious microarray resource. For instance, our module based analysis reveals that some of our modules relate to
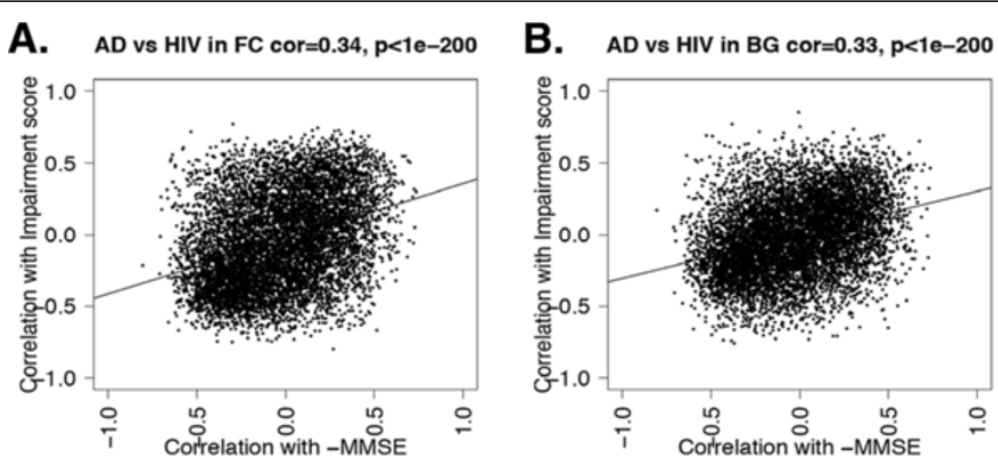

Figure 6 Common impairment marker genes across regions and diseases. Correlation between Impairment and gene expression in the hippocampus of Alzheimer's disease is relatively consistent with correlation between impairment and gene expression in frontal cortex (A) and basal ganglia (B) of HIV-associated neurocognitive disorder. The x-axes represent correlation with GCR score in HIV brains, while the y-axes represent negative correlation with MMSE in the AD brains. Dots in the upper right of the plot represent genes whose increased expression in either HIV of AD would suggest impairment, while dots in the lower left represent genes whose decreased expression would suggest impairment. 
Table 5 Enriched GO categories for common impairment genes

\begin{tabular}{|c|c|c|c|c|c|c|}
\hline \multicolumn{7}{|c|}{ Genes down-regulated with impairment in both AD and HIV } \\
\hline Gene Category & List Hits & List Total & Pop Hits & Pop Total & EASE score & Bonferroni \\
\hline Cytoplasm & 175 & 259 & 2277 & 4968 & $5.62 \mathrm{E}-13$ & 1.40E-09 \\
\hline Energy pathways & 26 & 259 & 128 & 5016 & 4.16E-09 & $1.04 \mathrm{E}-05$ \\
\hline Mitochondrion & 48 & 259 & 396 & 4968 & 3.27E-08 & $8.15 \mathrm{E}-05$ \\
\hline Tricarboxylic acid cycle & 10 & 259 & 20 & 5016 & $2.24 \mathrm{E}-07$ & $5.58 \mathrm{E}-04$ \\
\hline Transit peptide & 28 & 217 & 184 & 4007 & $1.14 \mathrm{E}-06$ & 2.85E-03 \\
\hline Synaptic vesicle & 10 & 259 & 30 & 4968 & $1.31 \mathrm{E}-05$ & $3.26 \mathrm{E}-02$ \\
\hline \multicolumn{7}{|c|}{ Genes up-regulated with impairment in both AD and HIV } \\
\hline Cell differentiation & 10 & 131 & 90 & 5016 & $4.79 \mathrm{E}-13$ & 1.40E-09 \\
\hline Activator & 11 & 105 & 131 & 4007 & 1.89E-03 & $1.00 \mathrm{E}+00$ \\
\hline Repeat & 42 & 105 & 1051 & 4007 & $1.98 \mathrm{E}-03$ & $1.00 E+00$ \\
\hline Cell communication & 50 & 131 & 1363 & 5016 & $5.20 \mathrm{E}-03$ & $1.00 \mathrm{E}+00$ \\
\hline Regulation of transcription & 32 & 131 & 762 & 5016 & $5.70 \mathrm{E}-03$ & $1.00 \mathrm{E}+00$ \\
\hline Phosphorylation & 26 & 105 & 582 & 4007 & $6.18 \mathrm{E}-03$ & $1.00 \mathrm{E}+00$ \\
\hline
\end{tabular}

All genes in this list were correlated with MMSE in Blalock et al. [25] $(R>0.25)$, as well as with GCR in the current analysis of HIV brains (both FC and BG, R $>0.25)$.

cell types. Specifically, we found that the Red module within the FC (6a), enriched with oligodendrocyterelated genes, was particularly elevated in the HIVE group (Group D), suggesting specific dysfunction of this cell type in those with HIVE. In addition, our modulebased analysis led to somewhat different enrichment of GO categories, and also provides a framework for understanding how various pathways interact through coexpression. For example, Gelman et al. identified 2 upregulated canonical pathways within the FC of individuals with HIVE, consisting of interferon signaling and activation of IRF cytosolic pattern recognition receptors. In comparison, the WGCNA identified 2 upregulated modules, consisting of a much wider array of pathways. The first module indicated increased transcription, DNA binding, and oligodendrocyte-related functioning, while the second indicated increased lysosome, lytic vacuole, glycosidase, antigen presentation, and interferon induction. Further, while Gelman identified 11 downregulated pathways within the FC of those with HIVE, our analysis indicated a single module consisting largely of pathways involved in hydrogen ion transporter activity, monovalent inorganic cation transporter activity, mitochondrion functioning, and

Table 6 Brain cell-specific alterations common to AD and HIV

\begin{tabular}{ccc}
\hline Direction of change & Cell type enrichment & Bonferroni \\
\hline Down with impairment & Neuron (probable) & $3.68 \mathrm{E}-12$ \\
Down with impairment & Neuron (definite)* & $1.13 \mathrm{E}-04$ \\
Up with impairment & Astrocyte (probable) & $3.34 \mathrm{E}-12$ \\
\hline
\end{tabular}

* Definite (10+ fold) and probable (1.5+ fold) enrichment from Cahoy et al. [53]. transporter activity. As such, it is possible that our single module represents a meta-pathway that encompasses many of the GO pathways identified by the previous approach, as well as some that were not detected previously. Together, the WGCNA reveals different canonical pathways associated with HIVE, allows for a more systems-based interpretation of the data, and provides insight into the interactive activity of the various canonical transcription pathways.

Further extending the findings of the previous study, we examined the relationship between HIV-associated neurocognitive impairment $(\mathrm{NCI})$ and gene expression, without making a distinction between those with or without HIVE. The reason for this approach is based on the poor correlation between HIVE and neurocognitive deficits that are characteristic of HAND [2,3], suggesting that biological processes that do not inevitably culminate in HIVE underlie neurocognitive changes in those with HIV. We used two methods; 1) correlating standard differential gene expression with GDS, and 2) correlating modules derived via co-expression matrices with GDS. Our two methods revealed very different findings, both worthy of further exploration. First, using standard differential expression analyses coupled with a bioinformatics networking program, we identified three notable genes within the WM network. Expression of the inhibitor of DNA binding gene (ID2) was negatively correlated with NCI, such that expression of this gene decreased with higher NCI. The ID pathway has been implicated in reactive gliosis [56], and is upregulated by proinflammatory cytokines implicated in HAND [57]. Another apparently relevant gene showing modest connectivity is death-associated protein (DAP). The 
Table 7 Common genes correlated with neurocognitive impairment in AD and HIV

\begin{tabular}{|c|c|c|c|c|}
\hline \multirow{2}{*}{$\begin{array}{l}\text { Gene } \\
\text { probe } \\
\text { Up with } \\
\text { impairment }\end{array}$} & \multirow[t]{2}{*}{ Function* } & \multicolumn{3}{|c|}{$\begin{array}{l}\text { Scaled intramodule connectivity } \\
\mathrm{kIN} / \max (\mathrm{kIN})\end{array}$} \\
\hline & & $\begin{array}{l}\text { AD } \\
\text { hippocampus }\end{array}$ & $\begin{array}{l}\text { HIV frontal } \\
\text { cortex }\end{array}$ & $\begin{array}{l}\text { HIV basal } \\
\text { ganglia }\end{array}$ \\
\hline CTDSP2 & Cancer & 1.0 & 1.0 & 1.0 \\
\hline SASH1 & Cancer & 0.84 & 0.95 & - \\
\hline FBXW12 & & 0.86 & - & 0.79 \\
\hline HIPK2 & Cancer & 0.77 & 0.74 & 0.72 \\
\hline CASC3 & Cancer & 0.74 & - & 0.74 \\
\hline CEP350 & & 0.72 & 0.90 & - \\
\hline PGF & Cancer & 0.71 & - & 0.73 \\
\hline HS1BP3 & Neurologic & 0.71 & - & 0.72 \\
\hline $\begin{array}{l}\text { Down with } \\
\text { Impairment }\end{array}$ & & $\begin{array}{l}\text { AD } \\
\text { hippocampus }\end{array}$ & $\begin{array}{l}\text { HIV frontal } \\
\text { cortex }\end{array}$ & $\begin{array}{l}\text { HIV basal } \\
\text { ganglia }\end{array}$ \\
\hline SCG5 & Neurologic & 0.96 & - & 0.85 \\
\hline VDAC1 & Mitochondria & 0.95 & 0.99 & 0.92 \\
\hline KIAA1279 & Neurologic & 0.93 & - & 0.70 \\
\hline PFDN4 & & 0.92 & 0.84 & - \\
\hline $\mathrm{MDH1}$ & Mitochondria & 0.90 & 0.84 & 1.0 \\
\hline ATP5G3 & Mitochondria & 0.90 & 0.95 & 0.99 \\
\hline DYNC111 & Neurologic & 0.89 & 0.83 & 0.83 \\
\hline PCMT1 & Neurologic & 0.86 & 0.98 & 0.90 \\
\hline TOMM20 & Mitochondria & 0.86 & - & 0.92 \\
\hline $\mathrm{KLC1}$ & Microtubule & 0.86 & 0.96 & - \\
\hline NDFIP1 & & 0.86 & 0.73 & 0.84 \\
\hline KIFAP3 & Neurologic & 0.85 & 0.87 & - \\
\hline THYN1 & & 0.85 & 0.74 & 0.78 \\
\hline GOT1 & Mitochondria & 0.84 & 0.83 & 0.84 \\
\hline TBC1D9 & & 0.84 & 0.75 & 0.90 \\
\hline UCHL1 & Neurologic & 0.84 & 0.84 & 0.92 \\
\hline ACTR10 & & 0.84 & 0.88 & 0.85 \\
\hline CISD1 & Mitochondria & 0.83 & 0.83 & 0.75 \\
\hline SMAP1 & & 0.82 & 0.76 & - \\
\hline C14orf2 & & 0.82 & 0.77 & 0.76 \\
\hline PEX11B & & 0.81 & 0.93 & - \\
\hline SLC4A1AP & & 0.81 & 0.71 & - \\
\hline COPS4 & & 0.81 & 0.87 & 0.79 \\
\hline ITFG1 & & 0.80 & 0.84 & 0.76 \\
\hline GLOD4 & & 0.79 & - & 0.83 \\
\hline DNAJA2 & Mitochondria & 0.78 & 0.74 & 0.73 \\
\hline SUCLA2 & Mitochondria & 0.76 & 0.87 & 0.84 \\
\hline NDUFB6 & & 0.76 & - & 0.78 \\
\hline EBNA1BP2 & & 0.76 & - & 0.72 \\
\hline TUBA4A & & 0.75 & - & - \\
\hline HINT1 & Cancer & 0.75 & 0.86 & 0.80 \\
\hline
\end{tabular}

Table 7 Common genes correlated with neurocognitive impairment in AD and HIV (Continued)

\begin{tabular}{lllll}
\hline ATP6V1E1 & Mitochondria & 0.74 & - & 0.75 \\
GUCY1B3 & & 0.72 & 0.83 & 0.91 \\
ATP5H & Neurologic & 0.72 & 0.73 & - \\
GPI & & 0.70 & 0.75 & - \\
BEX1 & Neurologic & 0.70 & - & 0.72
\end{tabular}

*Gene function was determined by reviewing information within the Online Mendelian Inheritance in Man database http://www.ncbi.nlm.nih.gov/sites/ entrez?db=omim.

findings of Deiss [58] suggest that DAP is one of two genes that mediate gamma-interferon induced apoptosis. Importantly, gamma-interferon has long been known to play a significant role in HIV-related neuropathology $[59,60]$. Of note, the fact that ID2 and DAP were negatively correlated with $\mathrm{NCI}$ goes against expectation, considering their reported neurobiological roles and associations with HIV-related immune factors. A third relevant gene, that showed strong positive correlation with NCI, is GRK6. GRK6 is involved in dopamine sensitivity at the D2 receptor [61]. Dysfunction of the dopaminergic neural systems, such as the frontostriatal system, has been strongly implicated in the etiology of HAND [62-67]. As such, one possible scenario is that upregulation of GRK6 results in desensitization of D2 receptors within the frontostriatal system, leading to increased NCI. Desensitization of D2 receptors may in turn lead to upregulated transcription. The complex balance of dopaminergic tone, mediated largely by the D2 receptor, was recently described by Gelman et al., who found that downregulation of D2 transcripts in HIV + human prefrontal cortex was associated with more favorable neuropsychological and neuropathological outcomes [68], underscoring the possible role of this receptor in the etiology of HAND. Of note, chemokine (C-C motif) ligand 2 (CCL2), also known as monocyte chemotactic protein-1, is also shown in this network, and has been repeatedly implicated in HAND [69-72]. Secondly, we explored GO categories associated with NCI. Notably, statistically significant downregulated GO categories were found only in the FC. Categories included the mitochondrion, mitotic cell cycle, DNA repair, proteasome complex, and nucleus. Together, these findings implicate a general breakdown of cellular functioning within the FC, including energy depletion and catabolism of intracellular waste products. Dysregulation of proteasome functioning was implicated in the FC. Proteasome dysfunction was previously reported in studies that related gene expression to pre-mortem neurocognitive functioning [73,74]. Enriched GO categories were identified in all three brain regions, including transcription regulation in both FC and WM, and homo sapiens 19 in WM and BG. The homo sapiens 19 category 
contains a large number of brain-related genes. Finally, we employed WGCNA to examine co-expression modules associated with NCI. Largely confirming the GO analysis, we found modules in the FC largely representative of transcription and cellular signaling and glycoprotein functioning that showed significant positive correlation with impairment. However, in addition to these pathways, another module representative of oligodendrocyte functioning showed a notable trend $(\mathrm{p}=.052)$ for positive correlation in the FC. This module was also positively correlated with $\mathrm{NCI}$ in the WM. Within the Red module in WM (6c), hub genes included those implicated in other neurological conditions and CNS functioning, including WNK1 (linked to both cardiovascular [75] and Alzheimer's disease [76]) and NEO1 (involved in nervous system development and apoptosis [77]). Interestingly, a larger module more prominently associated with oligodendrocytes (11c/Turquoise) does not show increased expression with $\mathrm{NCI}$, suggesting that only a subset of oligodendrocyteassociated genes may be related to HAND. These results suggest that a more in depth look at oligodendrocytes in relation to HAND may be warranted, particularly given recent implications of the role of oligodendrocytes in HAND and HIVE [78-80], as well as other neurodegenerative diseases, including $\mathrm{AD}[81,82]$. Indeed, considering the prominence of myelin pallor and gliosis as early neuropathological findings in AIDS patients, the role of oligodendrocyte-associated gene dysgregulation is not unexpected. Importantly, as these genes did not individually show significant correlations with $\mathrm{NCI}$, they would not have been detected in a standard differential expression analysis.

Both methods (standard differential expression analysis and WGCNA) here provide complementary interpretation of changes that occur in the brain with $\mathrm{NCI}$, and together provide a more complete look at NCI than either method alone. For example, both methods suggest that $\mathrm{NCI}$ is the result of increased transcription activity within the FC and WM. Further, both implicate decreased mitochondrial activity in the FC, and in the case of WGCNA, frontal white matter as well. Beyond that, standard analysis suggests that NCI is associated with downregulation of various networks or pathways involved in cellular functioning, energy metabolism, and proteasome functioning within the FC, as well as upregulation of categories such as transcription regulation in FC and WM, and Homo Sapiens 19 genes in WM and BG. Further, specific genes implicated include those involved in dopamine receptor sensitivity, apoptosis, and reactive gliosis. Conversely, WGNCA suggests that $\mathrm{NCI}$ is associated with increased transcription within the FC and WM. However, it also implicates oligodendrocyte dysfunction. Notably, the WGCNA did not identify any modules within the BG that were associated with NCI. Such divergent results are important, as they provide alternative directions for future investigations.

In study 1 we also examined the relationship between transcriptomic changes and antiretroviral therapy regimen, or more specifically CPE. The CPE is based on pharmacokinetic and pharmacodynamic characteristics of antiretroviral medications, including their ability to cross the blood brain barrier and eradicate HIV within the CNS [29]. In the current study, using differential expression analysis, only a few genes were found to have modest correlations with $\mathrm{CPE}$, and no GO categories were identified. Follow-up analysis with GNCPro in the WM revealed only a single gene with notable connectivity; TNPO3. TNPO3 is required for HIV-1 integration into the host DNA, and higher CPE would be expected to decrease its expression [51,52]. Counter intuitively, expression of this gene was positively correlated with CPE in the WM. Even when using WGCNA, no co-expression modules were found to be associated with $\mathrm{CPE}$, suggesting that higher penetrating regimens do not have a significant impact upon gene expression. While ours is the first study to examine the association between CPE and brain transcriptome in HIV, the relationship between combination antiretroviral therapy (cART) use and brain gene expression was recently described by Borjabad et al. [83]. Notably, they found that cART-treated cases had transcriptome signatures that more closely resembled those of HIVseronegative cases. Further, brains of individuals who were taking cART at the time of death had 83-93\% fewer dysregulated genes compared to untreated individuals. Despite this, in both treated and untreated HIV + brains there were approximately 100 dysregulated genes related to immune functioning, interferon response, cell cycle, and myelin pathways. Perhaps helpful in explaining our findings, gene expression in the HIV + brains did not correlate with brain viral burden, suggesting that even high CPE regimens, which have been shown to reduce CSF viral load [84], may not reduce transcriptomic dysregulation. Indeed, the absence of an association between CPE and brain transcriptome would help to explain the overall equivocal results thus far of studies examining the relationship between CPE and HIV-related NCI [31-33,85].

Study 2 sought to identify common transcriptome changes in HIV and AD that were related to NCI. Findings indicate some overlapping biological pathways underlying these two diseases. In total, 234 identical genes were upregulated and 413 downregulated in both diseases. Further, there was a modest correlation between HAND and AD in the level of correlation with cognitive impairment. More specifically, genes strongly correlated with NCI in HAND tend also to be strongly correlated with NCI in AD. Suppressed biological pathways associated with NCI in both diseases include cytoplasm, energy pathways, mitochondrion, tricarboxylic acid cycle, transit peptide, 
and synaptic vesicle. Conversely, expression of genes involved in cell differentiation, activator, repeat, cell communication, regulation of transcription, and phosphorylation increased with severity of $\mathrm{NCI}$ in both diseases. With regards to specific cell types, expression of neuronal marker genes was reduced with increasing NCI in both diseases, whereas expression of marker genes for astrocytes increased with NCI. Together, a picture emerges of waning neuronal functioning and waxing astrocytosis underlying the progressive neurocognitive decline in both diseases. This is further indicated by the results of cellular composition analysis, which found that neuronal loss/dysfunction along with gliosis underlies the impairment signature common to HIV and $\mathrm{AD}$, a finding that is consistent with previous studies of $\mathrm{AD}[86,87]$ and HAND [88-90]. Notably, examination of genes with greatest intramodular connectivity that are common between $\mathrm{AD}$ and HIV confirmed the down-regulation of mitochondrial-related genes in relation to $\mathrm{NCI}$ in both diseases; however, it also revealed a disproportionate number of cancer-related genes that were upregulated in both groups. This included genes in which upregulation is implicated in cancer (CTDSP2, CASC3, PGF) and those that are thought to be involved in tumor suppression (SASH1, HIPK2). The significance of these findings is unclear. Note that a recently published meta-analysis compared brain transcriptomes (frontal grey and/or frontal white matter) from individuals with HIVE and/or HAND to those from individuals with $\mathrm{AD}$ (various anatomic locations), without consideration of NCI [91]. Due to the different methodologies used, and the lack of specific anatomical focus (which as demonstrated here can lead to vastly different results), these two studies are not directly comparable.

While the findings of the current studies are compelling, they should be considered with the following caveats. First, the HIV + sample, while wellcharacterized both pre and post-mortem, was small. This in turn limited the power of our statistical analyses, and as such we have largely reported trends rather than statistically significant findings. While this limits the impact of our findings, we hope that they may still stimulate questions and new avenues for investigation. Second, the association of pre-mortem clinical data with post-mortem transcriptome data is fraught with difficulties, including variable time ranges between data collection, questionable reliability of psychometric testing among the very ill, uncertainty of adherence to ARV regimen, and effects of different causes of mortality upon brain transcription, to name a few. Finally, the comparison of $\mathrm{AD}$ and HIV brains involved different anatomical regions, which may have distinct transcription pathways regardless of disease state.

\section{Conclusion}

In summary, we provide here a systems biological interpretation of brain transcriptome data derived from HIV + individuals and those with Alzheimer's disease. Our results build upon previous findings that utilized a different grouping and analytic approach, and add an important dimension to understanding HIV-neuropathogenesis from a systems perspective. In addition, the identification of common pathways and genes associated with NCI in HIV and Alzheimer's disease is a novel finding that we believe warrants further investigation.

\section{Additional files}

Additional file 1: Correlations between gene expression and clinical variables (CPE scores and neurocognitive impairment).

Additional file 2: Hub genes and gene ontology enrichment for all modules found among the four clinically/neuropathologically-defined groups.

Additional file 3: Gene ontology enrichment for the modules related to neurocognitive impairment in the frontal cortex.

\section{Competing interests}

Dr. Horvath developed weighted gene coexpression network analysis, the primary analytic method described in this paper. He does not make direct profits from this tool, which is freely available online.

\section{Authors' contributions}

$A L, J M$, and SH initially conceived the projects and developed the methods and statistical approach. AL and JM were the primary authors of the text. JM and $\mathrm{SH}$ conducted the various statistical analyses and were also involved in the interpretation of the results. BG conducted the initial microarray of HIV + brains, and provided the data. He was also involved in manuscript preparation and provided invaluable input. PS conducted the GNCPro analysis and provided related interpretation. IG, SM, ES, DC, and $\mathrm{CH}$ are all key members of the NNTC, and were instrumental in providing data for the study, interpretation of results, and manuscript preparation. All authors have approved of the final version of this manuscript.

\section{Acknowledgements}

This study was funded in through the National NeuroAIDS Tissue Consortium, which consists of National Neurological AIDS Bank (U01MH08021 and R24-NS38841 - Singer), Texas NeuroAIDS Research Center (U01-MH083507 and R24-NS45491 - Gelman), Manhattan HIV Brain Bank (U01-MH083501 and R24-MH59724 - Morgello), and California NeuroAIDS Tissue Network (U01-MH083506 and R24-MH59745 - Grant). Funding was also provided by the National Institute for Drug Abuse grant R01DA030913 (Levine \& Horvath)

\section{Author details}

'Department of Neurology, National Neurological AIDS Bank, David Geffen School of Medicine at the University of California, Los Angeles, CA, USA. ${ }^{2}$ Department of Human Genetics, David Geffen School of Medicine at the University of California, Los Angeles, CA, USA. ${ }^{3}$ Department of Medicine (Division of Infectious Disease \& International Medicine) and Department of Psychiatry \& Behavioral Medicine, Morsani College of Medicine, University of South Florida, Tampa, FL, USA. ${ }^{4}$ Departments of Pathology and Neuroscience \& Cell Biology, University of Texas Medical Branch, Galveston, USA.

${ }^{5}$ Department of Psychiatry and Biobehavioral Sciences, David Geffen School of Medicine at the University of California, Los Angeles, CA, USA. 'VA Greater Los Angeles Healthcare System, Los Angeles, CA, USA. ${ }^{7}$ Department of Pathology, Keck School of Medicine at the University of Southern California, Los Angeles, CA, USA. ${ }^{8}$ Departments of Neurology, Neuroscience, and Pathology, Manhattan HIV Brain Bank, The Mount Sinai School of Medicine, New York, USA. ${ }^{9}$ Department of Psychiatry, California NeuroAIDS Tissue 
Network, University of California, San Diego, USA. ${ }^{10}$ Department of Biostatistics, University of California, Los Angeles, CA, USA.

Received: 4 September 2012 Accepted: 30 January 2013 Published: 13 February 2013

\section{References}

1. Antinori A, Arendt G, Becker JT, Brew BJ, Byrd DA, Cherner M, Clifford DB, Cinque P, Epstein LG, Goodkin K, et al: Updated research nosology for HIVassociated neurocognitive disorders. Neurology 2007, 69(18):1789-1799.

2. Cherner M, Cysique L, Heaton RK, Marcotte TD, Ellis RJ, Masliah E, Grant I: Neuropathologic confirmation of definitional criteria for human immunodeficiency virus-associated neurocognitive disorders. I Neurovirol 2007, 13(1):23-28.

3. Everall I, Vaida F, Khanlou N, Lazzaretto D, Achim C, Letendre S, Moore D, Ellis R, Cherner M, Gelman B, et al: Cliniconeuropathologic correlates of human immunodeficiency virus in the era of antiretroviral therapy. J Neurovirol 2009, 15(5-6):360-370.

4. Masliah E, Roberts ES, Langford D, Everall I, Crews L, Adame A, Rockenstein E, Fox HS: Patterns of gene dysregulation in the frontal cortex of patients with HIV encephalitis. J Neuroimmunol 2004, 157(1-2):163-175.

5. Salaria S, Badkoobehi H, Rockenstein E, Crews L, Chana G, Masliah E, Everall IP: Toll-like receptor pathway gene expression is associated with human immunodeficiency virus-associated neurodegeneration. J Neurovirol 2007, 13(6):496-503.

6. Everall I, Salaria S, Roberts E, Corbeil J, Sasik R, Fox H, Grant I, Masliah E: Methamphetamine stimulates interferon inducible genes in HIV infected brain. J Neuroimmunol 2005, 170(1-2):158-171.

7. Winkler JM, Chaudhuri AD, Fox HS: Translating the brain transcriptome in NeuroAIDS: from Non-human primates to humans. J Neuroimmune Pharmacol 2012, 7(2):372-379.

8. Roberts ES, Zandonatti MA, Watry DD, Madden LJ, Henriksen SJ, Taffe MA, Fox HS: Induction of pathogenic sets of genes in macrophages and neurons in NeuroAIDS. Am J Pathol 2003, 162(6):2041-2057.

9. Gersten M, Alirezaei M, Marcondes MC, Flynn C, Ravasi T, Ideker T, Fox HS: An integrated systems analysis implicates EGR1 downregulation in simian immunodeficiency virus encephalitis-induced neural dysfunction. J Neurosci 2009, 29(40):12467-12476.

10. Borjabad A, Brooks Al, Volsky DJ: Gene expression profiles of HIV-1 -infected glia and brain: toward better understanding of the role of astrocytes in HIV-1-associated neurocognitive disorders. J Neuroimmune Pharmacol 2010, 5(1):44-62

11. Gelman BB, Chen T, Lisinicchia JG, Soukup VM, Carmical RS, Starkey JM, Masliah E, Commins DL, Brandt D, Grant I, Singer EJ, Levine AJ, Miller J, Luxon BA, Morgello S: The national NeuroAIDS tissue consortium brain gene array: Two types of HIV-associated neurocognitive impairment. PLoS One, . In Press.

12. Gelman BM DJ: HIV-1 neuropathology. In Neurology of AIDS. Thirdth edition. Edited by Gendelman HE, Fox SH, Lipton SA, Everall IP, Grant I, Swindells S.: Oxford University Press; 2012:518-535.

13. Langfelder $\mathrm{P}$, Horvath $\mathrm{S}$ : WGCNA: an R package for weighted correlation network analysis. BMC Bioinforma 2008, 9:559.

14. Hu S, Zhou M, Jiang J, Wang J, Elashoff D, Gorr S, Michie SA, Spijkervet FK, Bootsma H, Kallenberg CG, et al: Systems biology analysis of Sjogren's syndrome and mucosa-associated lymphoid tissue lymphoma in parotid glands. Arthritis Rheum 2009, 60(1):81-92.

15. Horvath S, Zhang B, Carlson M, Lu KV, Zhu S, Felciano RM, Laurance MF, Zhao W, Qi S, Chen Z, et al: Analysis of oncogenic signaling networks in glioblastoma identifies ASPM as a molecular target. Proc Natl Acad Sci U S A 2006, 103(46):17402-17407.

16. Oldham MC, Konopka G, Iwamoto K, Langfelder P, Kato T, Horvath S, Geschwind DH: Functional organization of the transcriptome in human brain. Nat Neurosci 2008, 11(11):1271-1282.

17. Langfelder $P$, Luo R, Oldham MC, Horvath S: Is my network module preserved and reproducible? PLoS Comput Biol 2011, 7(1):e1001057.

18. Miller JA, Horvath S, Geschwind DH: Divergence of human and mouse brain transcriptome highlights alzheimer disease pathways. Proc Natl Acad Sci U S A 2010, 107(28):12698-12703.

19. Hilliard AT, Miller JE, Fraley ER, Horvath S, White SA: Molecular microcircuitry underlies functional specification in a basal ganglia circuit dedicated to vocal learning. Neuron 2012, 73(3):537-552.
20. Fuller TF, Ghazalpour A, Aten JE, Drake TA, Lusis AJ, Horvath S: Weighted gene coexpression network analysis strategies applied to mouse weight. Mamm Genome 2007, 18(6-7):463-472.

21. Mason MJ, Fan G, Plath K, Zhou Q, Horvath S: Signed weighted gene coexpression network analysis of transcriptional regulation in murine embryonic stem cells. BMC Genomics 2009, 10:327.

22. Plaisier CL, Horvath S, Huertas-Vazquez A, Cruz-Bautista I, Herrera MF, TusieLuna T, Aguilar-Salinas C, Pajukanta P: A systems genetics approach implicates USF1, FADS3, and other causal candidate genes for familial combined hyperlipidemia. PLoS Genet 2009, 5(9):e1000642.

23. Presson AP, Sobel EM, Papp JC, Suarez CJ, Whistler T, Rajeevan MS, Vernon $\mathrm{SD}$, Horvath S: Integrated weighted gene co-expression network analysis with an application to chronic fatigue syndrome. BMC Syst Biol 2008, 2:95.

24. Saris CG, Horvath $S$, van Vught PW, van Es MA, Blauw HM, Fuller TF, Langfelder P, DeYoung J, Wokke JH, Veldink JH, et al: Weighted gene coexpression network analysis of the peripheral blood from amyotrophic lateral sclerosis patients. BMC Genomics 2009, 10:405.

25. Blalock EM, Geddes JW, Chen KC, Porter NM, Markesbery WR, Landfield PW: Incipient Alzheimer's disease: microarray correlation analyses reveal major transcriptional and tumor suppressor responses. Proc Natl Acad Sci U S A 2004, 101(7):2173-2178.

26. Shapshak P, Rodriguez HE, Kayathri R, Levine A, Chiappelli F, Minagar A: Alzheimer's disease and HIV associated dementia related genes: I. location and function. Bioinformation 2008, 2(8):348-357.

27. Minagar A, Shapshak P, Duran EM, Kablinger AS, Alexander JS, Kelley RE, Seth R, Kazic T: HIV-associated dementia, Alzheimer's disease, multiple sclerosis, and schizophrenia: gene expression review. J Neurol Sci 2004, 224(1-2):3-17

28. Miller JA, Oldham MC, Geschwind DH: A systems level analysis of transcriptional changes in Alzheimer's disease and normal aging J Neurosci 2008, 28(6):1410-1420.

29. Letendre S, Marquie-Beck J, Capparelli E, Best B, Clifford D, Collier AC, Gelman BB, McArthur JC, McCutchan JA, Morgello S, et al: Validation of the CNS penetration-effectiveness rank for quantifying antiretroviral penetration into the central nervous system. Arch Neurol 2008, 65(1):65-70.

30. Morgello S, Gelman BB, Kozlowski PB, Vinters HV, Masliah E, Cornford M, Cavert W, Marra C, Grant I, Singer EJ: The national NeuroAIDS tissue consortium: a new paradigm in brain banking with an emphasis on infectious disease. Neuropathol Appl Neurobiol 2001, 27(4):326-335.

31. Tozzi V, Balestra P, Bellagamba R, Corpolongo A, Salvatori MF, ViscoComandini U, Vlassi C, Giulianelli M, Galgani S, Antinori A, et al: Persistence of neuropsychologic deficits despite long-term highly active antiretroviral therapy in patients with HIV-related neurocognitive impairment: prevalence and risk factors. J Acquir Immune Defic Syndr 2007, 45(2):174-182

32. Cysique LA, Vaida F, Letendre S, Gibson S, Cherner M, Woods SP, McCutchan JA, Heaton RK, Ellis RJ: Dynamics of cognitive change in impaired HIV-positive patients initiating antiretroviral therapy. Neurology 2009, 73(5):342-348.

33. Marra CM, Lockhart D, Zunt JR, Perrin M, Coombs RW, Collier AC: Changes in CSF and plasma HIV-1 RNA and cognition after starting potent antiretroviral therapy. Neurology 2003, 60(8):1388-1390.

34. Lim WK, Wang K, Lefebvre C, Califano A: Comparative analysis of microarray normalization procedures: effects on reverse engineering gene networks. Bioinformatics 2007, 23(13):i282-288.

35. Oldham MC, Horvath S, Geschwind DH: Conservation and evolution of gene coexpression networks in human and chimpanzee brains. Proc Natl Acad Sci U S A 2006, 103(47):17973-17978.

36. Miller JA, Cai C, Langfelder P, Geschwind DH, Kurian SM, Salomon DR, Horvath S: Strategies for aggregating gene expression data: the collapseRows R function. BMC Bioinformatics 2011, 12:322.

37. Hosack DA, Dennis G Jr, Sherman BT, Lane HC, Lempicki RA: Identifying biological themes within lists of genes with EASE. Genome Biol 2003, 4(10):R70.

38. Liu GG, Fong E, Zeng X: GNCPro: navigate human genes and relationships through net-walking. Adv Exp Med Biol 2010, 680:253-259.

39. Lee HK, Hsu AK, Sajdak J, Qin J, Pavlidis P: Coexpression analysis of human genes across many microarray data sets. Genome Res 2004, 14(6):1085-1094.

40. Schug J, Schuller WP, Kappen C, Salbaum JM, Bucan M, Stoeckert CJ Jr: Promoter features related to tissue specificity as measured by Shannon entropy. Genome Biol 2005, 6(4):R33. 
41. Zhang B, Horvath S: A general framework for weighted gene coexpression network analysis. Stat Appl Genet Mol Biol 2005, 4:Article17.

42. Langfelder $P$, Horvath S: Eigengene networks for studying the relationships between co-expression modules. BMC Syst Biol 2007, 1:54

43. Voineagu I, Wang X, Johnston P, Lowe JK, Tian Y, Horvath S, Mill J, Cantor RM, Blencowe BJ, Geschwind DH: Transcriptomic analysis of autistic brain reveals convergent molecular pathology. Nature 2011, 474(7351):380-384

44. Ghazalpour A, Doss S, Zhang B, Wang S, Plaisier C, Castellanos R, Brozell A, Schadt EE, Drake TA, Lusis AJ, et al: Integrating genetic and network analysis to characterize genes related to mouse weight. PLoS Genet 2006, 2(8):e130.

45. Ravasz E, Somera AL, Mongru DA, Oltvai ZN, Barabasi AL: Hierarchical organization of modularity in metabolic networks. Science 2002, 297(5586):1551-1555.

46. Yip AM, Horvath S: Gene network interconnectedness and the generalized topological overlap measure. BMC Bioinforma 2007, 8:22

47. Langfelder $P$, Zhang B, Horvath S: Defining clusters from a hierarchical cluster tree: the dynamic tree Cut package for R. Bioinformatics 2008, 24(5):719-720.

48. Horvath S, Dong J: Geometric interpretation of gene coexpression network analysis. PLoS Comput Biol 2008, 4(8):e1000117.

49. Folstein MF, Folstein SE, McHugh PR: "Mini-mental state". A practical method for grading the cognitive state of patients for the clinician. J Psychiatr Res 1975, 12(3):189-198.

50. Winston A, Duncombe C, Li PC, Gill JM, Kerr SJ, Puls R, Petoumenos K, Taylor-Robinson SD, Emery S, Cooper DA: Does choice of combination antiretroviral therapy (CART) alter changes in cerebral function testing after 48 weeks in treatment-naive, HIV-1-infected individuals commencing CART? A randomized, controlled study. Clin Infect Dis 2010, 50(6):920-929.

51. Zhou L, Sokolskaja E, Jolly C, James W, Cowley SA, Fassati A: Transportin 3 promotes a nuclear maturation step required for efficient HIV-1 integration. PLOS Pathog 2011, 7(8):e1002194.

52. De laco A, Luban J: Inhibition of HIV-1 infection by TNPO3 depletion is determined by capsid and detectable after viral cDNA enters the nucleus. Retrovirology 2011, 8:98.

53. Cahoy JD, Emery B, Kaushal A, Foo LC, Zamanian JL, Christopherson KS, Xing Y, Lubischer JL, Krieg PA, Krupenko SA, et al: A transcriptome database for astrocytes, neurons, and oligodendrocytes: a new resource for understanding brain development and function. J Neurosci 2008, 28(1):264-278

54. MacLennan NK, Dong J, Aten JE, Horvath S, Rahib L, Ornelas L, Dipple KM, McCabe ER: Weighted gene co-expression network analysis identifies biomarkers in glycerol kinase deficient mice. Mol Genet Metab 2009, 98(1-2):203-214

55. Heaton RK, Franklin DR, Ellis RJ, McCutchan JA, Letendre SL, Leblanc S, Corkran SH, Duarte NA, Clifford DB, Woods SP, et al: HIV-associated neurocognitive disorders before and during the era of combination antiretroviral therapy: differences in rates, nature, and predictors. J Neurovirol 2011, 17(1):3-16.

56. Aronica E, Vandeputte DA, van Vliet EA, da Silva FH L, Troost D, Gorter JA: Expression of Id proteins increases in astrocytes in the hippocampus of epileptic rats. Neuroreport 2001, 12(11):2461-2465.

57. Tzeng SF, Kahn M, Liva S, De Vellis J: Tumor necrosis factor-alpha regulation of the Id gene family in astrocytes and microglia during CNS inflammatory injury. Glia 1999, 26(2):139-152.

58. Deiss LP, Feinstein $E$, Berissi $H$, Cohen $O$, Kimchi A: Identification of a novel serine/threonine kinase and a novel $15-\mathrm{kD}$ protein as potential mediators of the gamma interferon-induced cell death. Genes Dev 1995, 9(1):15-30.

59. Gendelman HE, Genis $P$, Jett M, Zhai QH, Nottet HS: An experimental model system for HIV-1-induced brain injury. Adv Neuroimmunol 1994, 4(3):189-193.

60. Pulliam L, Rempel H, Sun B, Abadjian L, Calosing C, Meyerhoff DJ: A peripheral monocyte interferon phenotype in HIV infection correlates with a decrease in magnetic resonance spectroscopy metabolite concentrations. AIDS 2011, 25(14):1721-1726.

61. Gainetdinov RR, Bohn LM, Sotnikova TD, Cyr M, Laakso A, Macrae AD, Torres GE, Kim KM, Lefkowitz RJ, Caron MG, et al: Dopaminergic supersensitivity in $\mathrm{G}$ protein-coupled receptor kinase 6-deficient mice. Neuron 2003 38(2):291-303
62. Kumar AM, Ownby RL, Waldrop-Valverde D, Fernandez B, Kumar M: Human immunodeficiency virus infection in the CNS and decreased dopamine availability: relationship with neuropsychological performance. J Neurovirol 2011, 17(1):26-40.

63. Berger JR, Arendt G: HIV dementia: the role of the basal ganglia and dopaminergic systems. J Psychopharmacol 2000, 14(3):214-221.

64. Chang L, Wang GJ, Volkow ND, Ernst T, Telang F, Logan J, Fowler JS: Decreased brain dopamine transporters are related to cognitive deficits in HIV patients with or without cocaine abuse. Neuroimage 2008, 42(2):869-878.

65. di Rocco A, Bottiglieri T, Dorfman D, Werner P, Morrison C, Simpson D: Decreased homovanilic acid in cerebrospinal fluid correlates with impaired neuropsychologic function in HIV-1-infected patients. Clin Neuropharmacol 2000, 23(4):190-194.

66. Gelman BB, Spencer JA, Holzer CE 3rd, Soukup VM: Abnormal striatal dopaminergic synapses in National NeuroAIDS Tissue Consortium subjects with HIV encephalitis. J Neuroimmune Pharmacol 2006, 1(4):410-420.

67. Kumar AM, Fernandez JB, Singer EJ, Commins D, Waldrop-Valverde D, Ownby RL, Kumar M: Human immunodeficiency virus type 1 in the central nervous system leads to decreased dopamine in different regions of postmortem human brains. J Neurovirol 2009, 15(3):257-274

68. Gelman BB, Lisinicchia JG, Chen T, Johnson KM, Jennings K, Freeman DH Jr, Soukup VM: Prefrontal dopaminergic and enkephalinergic synaptic accommodation in HIV-associated neurocognitive disorders and encephalitis. J Neuroimmune Pharmacol 2012, 7(3):686-700

69. Conant K, Garzino-Demo A, Nath A, McArthur JC, Halliday W, Power C, Gallo RC, Major EO: Induction of monocyte chemoattractant protein-1 in HIV-1 Tat-stimulated astrocytes and elevation in AIDS dementia. Proc Natl Acad Sci U S A 1998, 95(6):3117-3121

70. Eugenin EA, Dyer G, Calderon TM, Berman JW: HIV-1 tat protein induces a migratory phenotype in human fetal microglia by a CCL2 (MCP-1)-dependent mechanism: possible role in NeuroAIDS. Glia 2005, 49(4):501-510.

71. Gonzalez E, Rovin BH, Sen L, Cooke G, Dhanda R, Mummidi S, Kulkarni H, Bamshad MJ, Telles V, Anderson SA, et al: HIV-1 infection and AIDS dementia are influenced by a mutant MCP-1 allele linked to increased monocyte infiltration of tissues and MCP-1 levels. Proc Natl Acad Sci U S A 2002, 99(21):13795-13800.

72. Weiss JM, Nath A, Major EO, Berman JW: HIV-1 Tat induces monocyte chemoattractant protein-1-mediated monocyte transmigration across a model of the human blood-brain barrier and up-regulates CCR5 expression on human monocytes. J Immunol 1999, 163(5):2953-2959.

73. Nguyen TP, Soukup VM, Gelman BB: Persistent hijacking of brain proteasomes in HIV-associated dementia. Am J Pathol 2010, 176(2):893-902.

74. Gelman BB, Nguyen TP: Synaptic proteins linked to HIV-1 infection and immunoproteasome induction: proteomic analysis of human synaptosomes. J Neuroimmune Pharmacol 2010, 5(1):92-102.

75. Newhouse SJ, Wallace C, Dobson R, Mein C, Pembroke J, Farrall M, Clayton D, Brown M, Samani N, Dominiczak A, et al: Haplotypes of the WNK1 gene associate with blood pressure variation in a severely hypertensive population from the British Genetics of Hypertension study. Hum Mol Genet 2005, 14(13):1805-1814.

76. Ray M, Ruan J, Zhang W: Variations in the transcriptome of Alzheimer's disease reveal molecular networks involved in cardiovascular diseases. Genome Biol 2008, 9(10):R148

77. Matsunaga E, Tauszig-Delamasure S, Monnier PP, Mueller BK, Strittmatter SM, Mehlen $P$, Chedotal A: RGM and its receptor neogenin regulate neuronal survival. Nat Cell Biol 2004, 6(8):749-755.

78. Cosenza MA, Zhao ML, Shankar SL, Shafit-Zagardo B, Lee SC: Up-regulation of MAP2e-expressing oligodendrocytes in the white matter of patients with HIV-1 encephalitis. Neuropathol App/ Neurobiol 2002, 28(6):480-488.

79. Lackner P, Kuenz B, Reindl M, Morandell M, Berger T, Schmutzhard E, Eggers C: Antibodies to myelin oligodendrocyte glycoprotein in HIV-1 associated neurocognitive disorder: a cross-sectional cohort study. J Neuroinflammation 2010, 7:79.

80. Jayadev S, Yun B, Nguyen H, Yokoo H, Morrison RS, Garden GA: The glial response to CNS HIV infection includes p53 activation and increased expression of p53 target genes. J Neuroimmune Pharmacol 2007, 2(4):359-370. 
81. Bartzokis $\mathrm{G}$ : Alzheimer's disease as homeostatic responses to age-related myelin breakdown. Neurobiol Aging 2011, 32(8):1341-1371.

82. Bartzokis G, Sultzer D, Lu PH, Nuechterlein KH, Mintz J, Cummings JL: Heterogeneous age-related breakdown of white matter structural integrity: implications for cortical "disconnection" in aging and Alzheimer's disease. Neurobiol Aging 2004, 25(7):843-851.

83. Borjabad A, Morgello S, Chao W, Kim SY, Brooks Al, Murray J, Potash MJ, Volsky DJ: Significant effects of antiretroviral therapy on global gene expression in brain tissues of patients with HIV-1-associated neurocognitive disorders. PLOS Pathog 2011, 7(9):e1002213.

84. Marra CM, Zhao Y, Clifford DB, Letendre S, Evans S, Henry K, Ellis RJ, Rodriguez B, Coombs RW, Schifitto G, et al: Impact of combination antiretroviral therapy on cerebrospinal fluid HIV RNA and neurocognitive performance. AIDS 2009, 23(11):1359-1366.

85. Garvey L, Winston A, Walsh J, Post F, Porter K, Gazzard B, Fisher M, Leen C, Pillay D, Hill T, et al: Antiretroviral therapy CNS penetration and HIV-1 -associated CNS disease. Neurology 2011, 76(8):693-700.

86. Serrano-Pozo A, Mielke ML, Gomez-Isla T, Betensky RA, Growdon JH, Frosch MP, Hyman BT: Reactive glia not only associates with plaques but also parallels tangles in Alzheimer's disease. Am J Pathol 2011, 179(3):1373-1384

87. Mandybur Tl: Cerebral amyloid angiopathy and astrocytic gliosis in Alzheimer's disease. Acta Neuropathol 1989, 78(3):329-331.

88. Xing HQ, Hayakawa H, Gelpi E, Kubota R, Budka H, Izumo S: Reduced expression of excitatory amino acid transporter 2 and diffuse microglial activation in the cerebral cortex in AIDS cases with or without HIV encephalitis. J Neuropathol Exp Neurol 2009, 68(2):199-209.

89. Gelman BB: Diffuse microgliosis associated with cerebral atrophy in the acquired immunodeficiency syndrome. Ann Neurol 1993, 34(1):65-70.

90. Paul RH, Yiannoutsos CT, Miller EN, Chang L, Marra CM, Schifitto G, Ernst T, Singer E, Richards T, Jarvik GJ, et al: Proton MRS and neuropsychological correlates in AIDS dementia complex: evidence of subcortical specificity. J Neuropsychiatry Clin Neurosci 2007, 19(3):283-292.

91. Borjabad A, Volsky DJ: Common Transcriptional Signatures in Brain Tissue from Patients with HIV-Associated Neurocognitive Disorders, Alzheimer's Disease, and Multiple Sclerosis. J Neuroimmune Pharmacol 2012, 7(4):914-926.

doi:10.1186/1755-8794-6-4

Cite this article as: Levine et al: Systems analysis of human brain gene expression: mechanisms for HIV-associated neurocognitive impairment and common pathways with Alzheimer's disease. BMC Medical Genomics $20136: 4$.

\section{Submit your next manuscript to BioMed Central and take full advantage of:}

- Convenient online submission

- Thorough peer review

- No space constraints or color figure charges

- Immediate publication on acceptance

- Inclusion in PubMed, CAS, Scopus and Google Scholar

- Research which is freely available for redistribution 